\title{
๖Understanding Intermodel Variability in Future Projections of a Sahelian Storm Proxy and Southern Saharan Warming $\mathscr{O}$
}

\author{
David P. Rowell, ${ }^{a}$ Rory G. J. FitzPATRICK, ${ }^{\mathrm{b}}$ LAwrenCE S. JACKSON, ${ }^{\mathrm{b}}$ AND GRACE REDMOND ${ }^{\mathrm{a}}$ \\ ${ }^{\mathrm{a}}$ Met Office Hadley Centre, Exeter, United Kingdom \\ ${ }^{\mathrm{b}}$ Institute for Climate and Atmospheric Sciences, University of Leeds, Leeds, United Kingdom
}

(Manuscript received 22 May 2020, in final form 6 October 2020)

\begin{abstract}
Projected changes in the intensity of severe rain events over the North African Sahel-falling from large mesoscale convective systems - cannot be directly assessed from global climate models due to their inadequate resolution and parameterization of convection. Instead, the large-scale atmospheric drivers of these storms must be analyzed. Here we study changes in meridional lower-tropospheric temperature gradient across the Sahel $\left(\Delta T_{\text {Grad }}\right)$, which affect storm development via zonal vertical wind shear and Saharan air layer characteristics. Projected changes in $\Delta T_{\text {Grad }}$ vary substantially among models, adversely affecting planning decisions that need to be resilient to adverse risks, such as increased flooding. This study seeks to understand the causes of these projection uncertainties and finds three key drivers. The first is intermodel variability in remote warming, which has strongest impact on the eastern Sahel, decaying toward the west. Second, and most important, a warming-advection-circulation feedback in a narrow band along the southern Sahara varies in strength between models. Third, variations in southern Saharan evaporative anomalies weakly affect $\Delta T_{\mathrm{Grad}}$, although for an outlier model these are sufficiently substantive to reduce warming here to below that of the global mean. Together these uncertain mechanisms lead to uncertain southern Saharan/northern Sahelian warming, causing the bulk of large intermodel variations

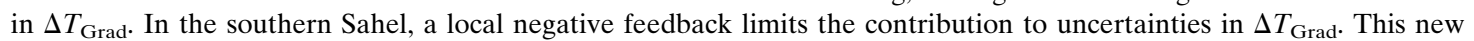
knowledge of $\Delta T_{\mathrm{Grad}}$ projection uncertainties provides understanding that can be used, in combination with further research, to constrain projections of severe Sahelian storm activity.
\end{abstract}

KEYWORDS: Africa; Feedback; Storm environments; Temperature; Climate prediction; General circulation models

\section{Introduction}

Mesoscale convective systems (MCSs) have a substantial impact on the vulnerable population of the North African Sahel. On the one hand they bring the majority of rainfall required for agriculture (e.g., Laurent et al. 1998; Laing et al. 1999; Lafore et al. 2011), but on the other hand, the most intense events can bring severe urban flooding (e.g., Engel et al. 2017; Lafore et al. 2017), damage to crops (e.g., Lobell and Gourdji 2012), and enhanced erosion (Panagos et al. 2017). Panthou et al. (2014) and Taylor et al. (2017) have found a substantial recent increase in the frequency of these severe events, with other studies showing a corresponding increase in flood frequency (Nka et al. 2015; Tazan et al. 2019; Wilcox et al. 2018). Globally, the frequency of intense rainfall events is expected to continue to increase as climate warms in response to rising anthropogenic carbon emissions (e.g., Kharin et al. 2013; Kendon et al. 2019), but at regional scales, the specific risks - measured for example by a "defensible plausible range"—are largely unknown. Yet

¿ Denotes content that is immediately available upon publication as open access.

Supplemental information related to this paper is available at the Journals Online website: https://doi.org/10.1175/JCLI-D-200382.s1.

Corresponding author: David P. Rowell, dave.rowell@metoffice. gov.uk such information is critical for today's decision makers who must incorporate future climate resilience into national, regional, and urban planning.

A significant difficulty in the provision of such information is that general circulation models (GCMs) - the primary tool for regional climate projection-are incapable of resolving MCSs, due to their coarse resolution and the complexity of deriving robust storm statistics within parameterized convection schemes. This raises concerns about the suitability of GCMs for predicting the changing risk in severe Sahelian storms; see for example Crook et al.'s (2019) assessment of the resolution and parameterization dependence of storm life cycles. In future, availability of an ensemble of convection-permitting models may overcome these difficulties, but this remains a distant prospect, with currently only one short time slice projection available for Africa (Kendon et al. 2019; Berthou et al. 2019; Fitzpatrick et al. 2020) due to their immense computing requirements. Yet, analysis of multiple models is essential to properly account for uncertainties arising from the range of plausible representations of the climate system. Hence, a scientifically robust risk-based approach, directly founded on climate model output and incorporating information on modeling uncertainty, is presently unfeasible.

In the meantime, a tractable solution could be an expert-informed downscaling approach, utilizing GCM-projected changes in a priori identified large-scale drivers of MCS behavior. A multimodel ensemble of these large-scale changes could then be transformed to a plausible range of the future change in MCS behavior via expert judgement of the relationships between large-scale and storm-scale (thermo)dynamics. These large-scale drivers must encompass a number of environmental factors determining the 
organization and intensity of Sahelian MCSs. One is the increasing moisture content of a warmer atmosphere, widely known to intensify storm dynamics (e.g., Collins et al. 2013; Berg et al. 2013; Singleton and Toumi 2013). Another is the low-level vertical wind shear below the African easterly jet (AEJ), which enhances convective organization, amplifying MCS intensity and longevity (e.g., Browning and Ludlam 1962; Mohr and Thorncroft 2006; Alfaro 2017). A third environmental driver is the influence of the midlevel warming and drying of the Saharan air layer (SAL), which 1) enhances convective inhibition, allowing greater accumulation of convective available potential energy, and hence more intense MCSs once triggered (Takemi 2007, 2010), and 2) enhances rainfall evaporation, aiding cold pool development, which is important for MCS organization and dynamics (e.g., Szeto and Cho 1994; Weisman and Rotunno 2004; Provod et al. 2016). We note, however, that regarding this last environmental driver, such detail in the thermodynamic profile of GCMs may be confounded by their convective parameterization, raising concerns about the suitability of SAL diagnostics as a large-scale driver. On the other hand, both shear and SAL characteristics are associated with the meridional gradient of lower tropospheric temperature across the Sahel, through its impact on baroclinicity below the AEJ and on SAL heat and moisture content above the Sahel, which is adiabatically connected to the Saharan boundary layer (Cook 1999; Parker et al. 2005; Pu and Cook 2010; Nicholson 2013). Understanding the GCM-projected changes and uncertainties in this meridional temperature gradient will form the focus of this study, laying some of the foundations required for further work to constrain projections of Sahelian storm activity.

Recent work has shown that GCM projections exhibit strongly enhanced warming over the Sahara. In the ensemble mean, this is due to a "desert amplification" mechanism, whereby limited surface latent heat release is compensated by greater surface warming and enhanced longwave and sensible heat release, alongside amplified moisture feedbacks due to longwave radiative sensitivities to the fractional change in water vapor (Zhou 2016). To our knowledge, intermodel variability of these mechanisms has yet to be examined, but nevertheless - in the ensemble mean at least - they induce an obvious enhancement of temperature gradients southward across the Sahel. Furthermore, this amplified Saharan warming has already become apparent in recent decades (Cook and Vizy 2015; Wei et al. 2017), with Vizy and Cook (2017) demonstrating its seasonal peak coincides with the Sahelian wet season. Taylor et al. (2017) have illustrated the consequential impact on recent trends in meridional temperature gradient across the Sahel and found this to be the major contributor to a dramatic rise in the frequency of intense storms over the last 35 years. Here we focus on future possibilities, evaluating the causes of intermodel variability in GCM projections of this meridional temperature gradient.

The paper is structured as follows. Section 2 describes the model data, defines the large-scale drivers of MCS activity, and quantifies their projection spread among models. To limit the scope of this study, further analysis then focuses on understanding the causes of intermodel variations in the projected change in low-level meridional temperature gradient across the Sahel, this being (as discussed above) a critical driver of MCS behavior. Understanding the causes of uncertainties in regional moisture change will be addressed in a subsequent paper. Section 3 explores the relative roles of remote and regional drivers of the uncertainty in temperature gradient change. Section 4 provides a more in-depth examination of the roles of regional lower tropospheric and surface processes in determining the intermodel variability, and section 5 concludes the study.

\section{Data, storm proxies, and intermodel spread}

\section{a. Model data}

Three experiments undertaken during phase 5 of the Coupled Model Intercomparison Project (CMIP5; Taylor et al. 2012) are analyzed here. Projection data are sourced from simulations forced by the representative concentration pathway 8.5 (RCP8.5), an emissions scenario with no specific climate mitigation targets, so providing large signal-to-noise ratios, and run by a large number of institutes, so providing good data availability. Reference data are from the "historical" simulation driven by realistic anthropogenic and natural forcings. Data from these experiments are averaged over 2070-99 and 1950-99, respectively. Additionally, in section 2c, the natural variability of each model is computed using its preindustrial control experiment ("piControl"), in which all external forcings (anthropogenic and natural) are fixed at preindustrial conditions. In this case, the first 20 years of any spinup is removed, and the remaining data (230-1031 years) detrended to remove any long-term drift.

For models and experiments with an initial condition ensemble, only the first member is analyzed for consistency across models. Also, all data are interpolated to a $1.25^{\circ}$ latitude $\times$ $1.875^{\circ}$ longitude grid (that of HadGEM2-ES) and averaged over July-September (JAS), which defines the Sahelian wet season (e.g., Lafore et al. 2011; Nicholson et al. 2018). Vertical discretization is determined by CMIP5's archiving of standard levels; in the lower troposphere these are 925, 850, 700, and $600 \mathrm{hPa}$.

Data are available for 40 models from the RCP8.5 and historical simulations for the key variables required: atmospheric temperature, near-surface air temperature, horizontal winds, and sea level pressure (SLP). These models are listed in Table 1. For other variables, some data from eight of these models were not available; the remaining models are referred to as the "32-model subset" in relevant figures, and are marked in the right-hand column of Table 1. Additionally, we have assessed the impact of the nonindependence of models (cf. Knutti et al. 2013; Sanderson et al. 2015), by repeating the analyses of Figs. 5 and 7 (as examples) using subensembles restricted to one model per institute. Almost identical patterns were found, and thus the interpretation presented here is unaffected.

\section{b. Large-scale drivers of MCS activity}

Following the discussion in section 1, three large-scale seasonal mean drivers of the frequency of intense MCS events are defined for initial analysis: 
TABLE 1. CMIP5 models' projected change in large-scale drivers of intense Sahel storms: meridional 850-hPa temperature gradient $\left(\Delta T_{\text {Grad }}\right), 925-600-h P a$ vertical zonal wind shear ( $\Delta$ Shear), and total column-integrated water vapor $(\Delta T C W)$. Data are averaged over the West, Central, and East Sahel (W, Cen, and E, respectively) and over July-September. TCW data are missing for EC-EARTH and HadGEM2-AO, and models are ordered by Cen $\Delta T_{\mathrm{Grad}}$. The right-hand column marks the 32-model subset for which all variables used in this article are available. Expansions of model acronyms are available at http://www.ametsoc.org/PubsAcronymList.

\begin{tabular}{|c|c|c|c|c|}
\hline Model name/version & $\Delta T_{\text {Grad }}(\mathrm{W}$, Cen, $\mathrm{E})$ & $\Delta$ Shear $(\mathrm{W}$, Cen, E) & $\Delta \mathrm{TCW}(\mathrm{W}, \mathrm{Cen}, \mathrm{E})$ & Data available for all variables \\
\hline MIROC5 & $-0.02,-0.04,0.02$ & $0.32,0.02,1.38$ & $13.1,15.4,16.5$ & $\checkmark$ \\
\hline CESM1(CAM5) & $0.06,0.02,0.00$ & $1.57,0.93,0.65$ & $11.9,13.6,14.3$ & \\
\hline FGOALS-g2 & $0.01,0.03,0.11$ & $1.12,0.75,2.14$ & $11.5,11.9,13.8$ & \\
\hline BNU-ESM & $-0.02,0.05,0.15$ & $-0.10,0.75,0.88$ & $18.0,19.9,20.6$ & $\checkmark$ \\
\hline CNRM-CM5 & $0.08,0.06,0.10$ & $1.31,0.98,1.05$ & $10.5,11.6,11.1$ & $\checkmark$ \\
\hline GFDL-ESM2G & $0.02,0.07,0.12$ & $1.25,1.94,1.88$ & $13.4,12.0,9.8$ & $\checkmark$ \\
\hline EC-EARTH & $0.11,0.10,0.11$ & $1.67,1.45,0.84$ &,,-- & \\
\hline GISS-E2-R & $0.12,0.12,0.09$ & $2.34,1.56,1.12$ & $8.7,10.5,8.4$ & $\checkmark$ \\
\hline GFDL-ESM2M & $0.06,0.12,0.04$ & $1.47,1.81,1.06$ & $13.0,10.2,8.2$ & $\checkmark$ \\
\hline CCSM4 & $0.11,0.13,0.15$ & $1.96,1.60,1.32$ & $10.5,12.9,12.5$ & $\checkmark$ \\
\hline GISS-E2-H-CC & $0.11,0.13,0.10$ & $2.29,1.73,1.34$ & $10.0,11.1,9.6$ & $\checkmark$ \\
\hline GISS-E2-H & $0.10,0.14,0.12$ & $2.15,1.86,1.01$ & $10.1,12.0,9.0$ & $\checkmark$ \\
\hline MPI-ESM-LR & $0.14,0.14,0.05$ & $1.85,1.29,0.96$ & $12.1,13.4,9.9$ & $\checkmark$ \\
\hline CESM1(BGC) & $0.12,0.14,0.17$ & $2.10,1.70,1.19$ & $10.3,12.7,12.5$ & $\checkmark$ \\
\hline BCC-CSM1.1 & $0.18,0.15,0.11$ & $2.33,0.54,-0.21$ & $9.8,9.1,8.4$ & $\checkmark$ \\
\hline GISS-E2-R-CC & $0.12,0.15,0.11$ & $2.59,1.95,1.03$ & $8.8,10.9,8.6$ & $\checkmark$ \\
\hline CSIRO-Mk3.6.0 & $0.28,0.15,0.11$ & $2.78,1.04,0.74$ & $10.6,13.1,11.9$ & $\checkmark$ \\
\hline GFDL CM3 & $0.11,0.15,0.23$ & $2.66,2.40,2.30$ & $20.1,20.7,18.5$ & $\checkmark$ \\
\hline FIO-ESM & $0.11,0.15,0.13$ & $2.26,1.60,0.78$ & $8.9,7.6,6.7$ & \\
\hline MPI-ESM-MR & $0.14,0.16,0.10$ & $1.84,1.74,1.34$ & $13.2,15.3,11.9$ & $\checkmark$ \\
\hline BCC-CSM1.1(m) & $0.11,0.16,0.14$ & $1.38,0.99,0.71$ & $9.2,10.9,10.8$ & $\checkmark$ \\
\hline IPSL-CM5B-LR & $0.17,0.16,0.15$ & $3.18,2.17,1.53$ & $9.3,10.8,9.7$ & $\checkmark$ \\
\hline MRI-ESM1 & $0.15,0.16,0.13$ & $1.98,1.60,0.86$ & $11.5,11.2,9.3$ & $\checkmark$ \\
\hline MRI-CGCM3 & $0.16,0.17,0.15$ & $2.12,1.67,1.15$ & $10.6,10.6,9.1$ & $\checkmark$ \\
\hline CMCC-CESM & $0.17,0.17,0.15$ & $1.82,1.67,1.02$ & $13.8,14.7,12.1$ & \\
\hline IPSL-CM5A-LR & $0.12,0.17,0.22$ & $1.81,1.60,1.66$ & $15.4,16.8,14.6$ & $\checkmark$ \\
\hline INM-CM4 & $0.13,0.17,0.20$ & $1.75,1.58,1.38$ & $3.5,6.1,6.7$ & $\checkmark$ \\
\hline CMCC-CM & $0.15,0.18,0.16$ & $2.29,1.85,1.58$ & $13.2,17.0,14.8$ & \\
\hline CMCC-CMS & $0.13,0.18,0.15$ & $2.11,1.91,1.22$ & $15.5,18.8,15.2$ & \\
\hline CanESM2 & $0.12,0.19,0.20$ & $2.35,2.09,3.01$ & $12.1,18.5,18.6$ & $\checkmark$ \\
\hline IPSL-CM5A-MR & $0.11,0.20,0.31$ & $1.84,2.25,2.80$ & $15.5,18.6,17.2$ & $\checkmark$ \\
\hline MIROC-ESM & $0.04,0.22,0.24$ & $2.41,3.35,2.19$ & $20.8,22.7,21.6$ & $\checkmark$ \\
\hline MIROC-ESM-CHEM & $0.05,0.23,0.27$ & $2.43,3.64,2.42$ & $22.0,24.1,22.3$ & \\
\hline NorESM1-ME & $0.20,0.25,0.23$ & $3.00,2.73,1.72$ & $10.8,12.5,11.8$ & $\checkmark$ \\
\hline NorESM1-M & $0.20,0.25,0.22$ & $3.18,3.03,1.86$ & $11.3,12.8,11.8$ & $\checkmark$ \\
\hline HadGEM2-ES & $0.20,0.30,0.33$ & $2.96,3.08,2.90$ & $11.6,16.0,15.3$ & $\checkmark$ \\
\hline ACCESS1.0 & $0.20,0.31,0.35$ & $2.61,2.89,2.42$ & $11.6,15.1,13.0$ & $\checkmark$ \\
\hline HadGEM2-AO & $0.19,0.32,0.35$ & $3.27,3.48,3.13$ &,,-- & $\checkmark$ \\
\hline HadGEM2-CC & $0.21,0.32,0.36$ & $3.12,3.58,3.05$ & $12.3,16.5,15.1$ & $\checkmark$ \\
\hline ACCESS1.3 & $0.27,0.34,0.33$ & $3.70,3.62,2.30$ & $13.4,14.6,13.8$ & $\checkmark$ \\
\hline
\end{tabular}

1) Meridional lower-tropospheric temperature gradient across the Sahel, hereafter $T_{\text {Grad. }}$ This will be the primary focus of this study. For a given region, it is defined by the slope of the linear regression between zonal mean $850-\mathrm{hPa}$ temperature and latitude (i.e., units of kelvin per degree of latitude). The level $850 \mathrm{hPa}$ is chosen to be representative of the mean temperature below the $600-\mathrm{hPa} \mathrm{AEJ}$ and also representative of the SAL.

2) Vertical zonal wind shear. This is shear below the AEJ and is computed as $925-\mathrm{hPa}$ minus $600-\mathrm{hPa}$ zonal winds, averaged over a given region. We expect changes in this driver to be well correlated across models with changes in $T_{\text {Grad }}$ (verified below) and so we choose to focus attention on
$T_{\text {Grad }}$ because it additionally encompasses influences of the SAL (section 1) as well as being the underlying cause of the vertical shear.

3) Total column-integrated water vapor (TCW). Again, this large-scale driver is defined as a spatial average over a given region, but after brief analysis here will be more extensively pursued in a parallel study.

The Sahel is split into three subregions, motivated by previous work showing distinct behavior of the projections of seasonal mean rainfall between the western and the combined central and eastern Sahel, either side of approximately $5^{\circ} \mathrm{W}$ (e.g., Biasutti 2013; James et al. 2014; Rowell et al. 2016). It 
Averaging Regions and Topography
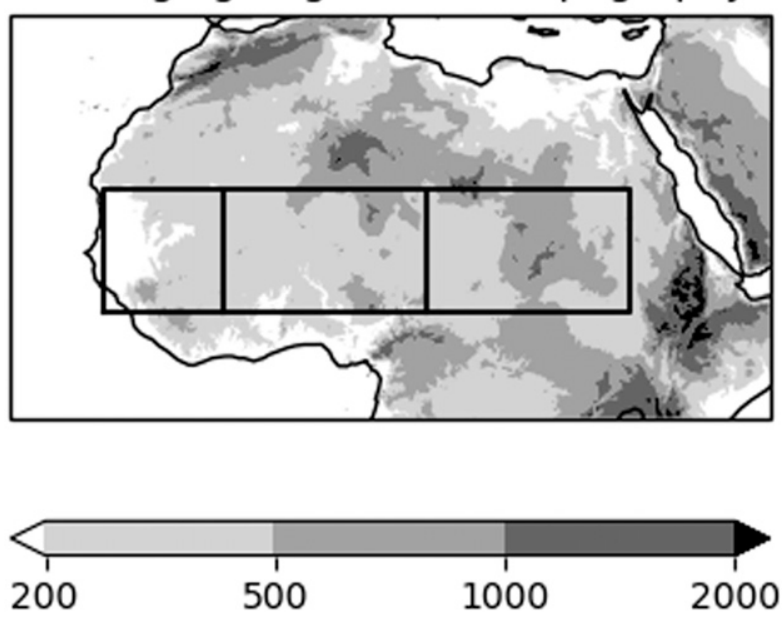

FIG. 1. The "West Sahel," "Central Sahel," and "East Sahel" averaging regions shown as boxes, overlaid on topographic height (m).

may be that similar zonal asymmetries are also apparent in the mechanisms and uncertainties of the large-scale storm drivers. These regions encompass a latitude range with grid-box centers from $10^{\circ}$ to $20^{\circ} \mathrm{N}$. The "West Sahel" region herein spans longitudes $15^{\circ} \mathrm{W}-5.625^{\circ} \mathrm{W}$, the "Central Sahel" spans $3.75^{\circ} \mathrm{W}-$ $13.125^{\circ} \mathrm{E}$ [so together the West and Central Sahel are similar to Taylor et al.'s (2017) $T_{\text {Grad }}$ region], and the "East Sahel", spans $15^{\circ}-33.75^{\circ} \mathrm{E}$ (grid box centers). These regions are illustrated in Fig. 1. In the context of this paper, their definitions are also supported by-and indeed partly founded on-the further analysis discussed in section 3 .

A final data processing issue is that many GCM simulations do not archive the subdaily resolution data that would ideally be required for quantifying the prestorm environment. Furthermore, and in any case, these models poorly represent the strong diurnal cycle of MCS occurrence (e.g., Yang and Slingo 2005; Marsham et al. 2013). We are thus obliged to analyze GCMs' all-day means, making the assumption that future changes in these means are well correlated across models with changes in a more discriminating measure of prestorm environment. We suspect this assumption is likely valid - that is, that the first-order component of a model's change in prestorm environment is its change in mean state, not least because of large intermodel variations in these changes in mean state (see below). However, this assumption can only be confirmed (or refuted) once multimodel projection ensembles become available with much improved tropical diurnal cycles.

\section{c. Intermodel spread}

Figure 2 shows late twenty-first-century projected changes in each of the large-scale drivers of intense Sahelian storms (data association to specific models is recorded in Table 1). Modeling uncertainty is substantial for all three drivers, and much larger than natural variability (estimated for 30-yr minus 50-yr differences, from each model's piControl data, emulating the period lengths defined in section 2a). These large ranges emphasize the extent of resilience options that must be built into adaptation decisions (cf. van Aalst et al. 2008; Kniveton et al. 2015), and conversely the value offered by efforts to reduce these climate modeling uncertainties. Note also that the distributions of Fig. 2 are not dominated by any outliers that would offer the prospect of large uncertainty reductions via evidence of unreliable behavior of just a few models (cf. Rowell 2019). Rather, each distribution is more or less continuous, apart from a few slight outliers with smaller changes in West Sahel shear (BNU-ESM and MIROC5), East Sahel shear (BCC-CSM1.1), and West Sahel TCW (INMCM4). Application of this analysis in a risk-based approach would note high vulnerability at the upper end of these distributions, and might for example consider adaptation measures resilient to the full projection range or to say the central $90 \%$.

The range of $T_{\text {Grad }}$ changes extend from near-zero to $0.35 \mathrm{~K}$ per degree of latitude. As expected, these are well correlated with intermodel variations in the change in shear (Fig. 3, top row), justifying our focus on $\Delta T_{\text {Grad }}$ (hereafter, $\Delta$ denotes RCP8.5minus-historical anomalies). Note also that $\Delta T_{\text {Grad }}$ uncertainty appears similar in the new CMIP6 ensemble (based on 16 models readily available at the time of writing, forced by the Shared Socioeconomic Pathway 5-8.5 that closely follows RCP8.5).

Uncertainties in $\triangle \mathrm{TCW}$ roughly span a factor of 4 (Fig. 2). These, perhaps not surprisingly, are moderately to well correlated across models with projected changes in JAS mean Sahel rainfall (Fig. 3, lower row). Since a parallel study (K. Sheen and D. Rowell, unpublished manuscript) aims to understand intermodel variations in seasonal Sahel rainfall change, and also includes analysis of $\Delta \mathrm{TCW}$, these uncertainties are not further pursued here.

Therefore, we now focus exclusively on understanding the causes of intermodel variations in the projected changes in 850$\mathrm{hPa}$ meridional temperature gradient $\Delta T_{\mathrm{Grad}}$.

\section{Remote versus regional contributions to uncertainty}

Intermodel variability in local temperature change in the lower troposphere is likely strongly related to the models' global mean temperature change; compare Macadam et al.'s (2020) analysis of near-surface air temperature anomalies or the temporal regional-global relationships used for pattern scaling (e.g., Mitchell 2003). In contrast, if we consider that changes in the gradient of regional temperature are the differential warming between two adjacent regions, then this remote influence may be partly_but not wholly—negated. Thus, uncertainties in $\Delta T_{\text {Grad }}$ may be relatively more impacted by the uncertain representation of processes in the immediate region.

The drivers of intermodel variability of $\Delta T_{\mathrm{Grad}}$ can therefore be classified into two distinct sets. The first set is remote drivers, which derive from diverse uncertainties in slow ocean warming, sea ice feedbacks, atmospheric feedbacks, land surface interactions, and so on. These drivers affect intermodel variability in North African warming via planetary-scale atmospheric mixing, and could-hypothetically-dominate regional uncertainties in $\Delta T_{\mathrm{Grad}}$ on the condition that the pattern of regional amplification of remote warming is consistent across models. The second set of drivers is then the intermodel variability in these regional processes and feedbacks. This could either manifest 1) through uncertainty in the regional pattern of the amplification of remote warming (e.g., land-sea contrasts), evolving slowly with the progressive warming of the global oceans, and/or 2) via uncertain 

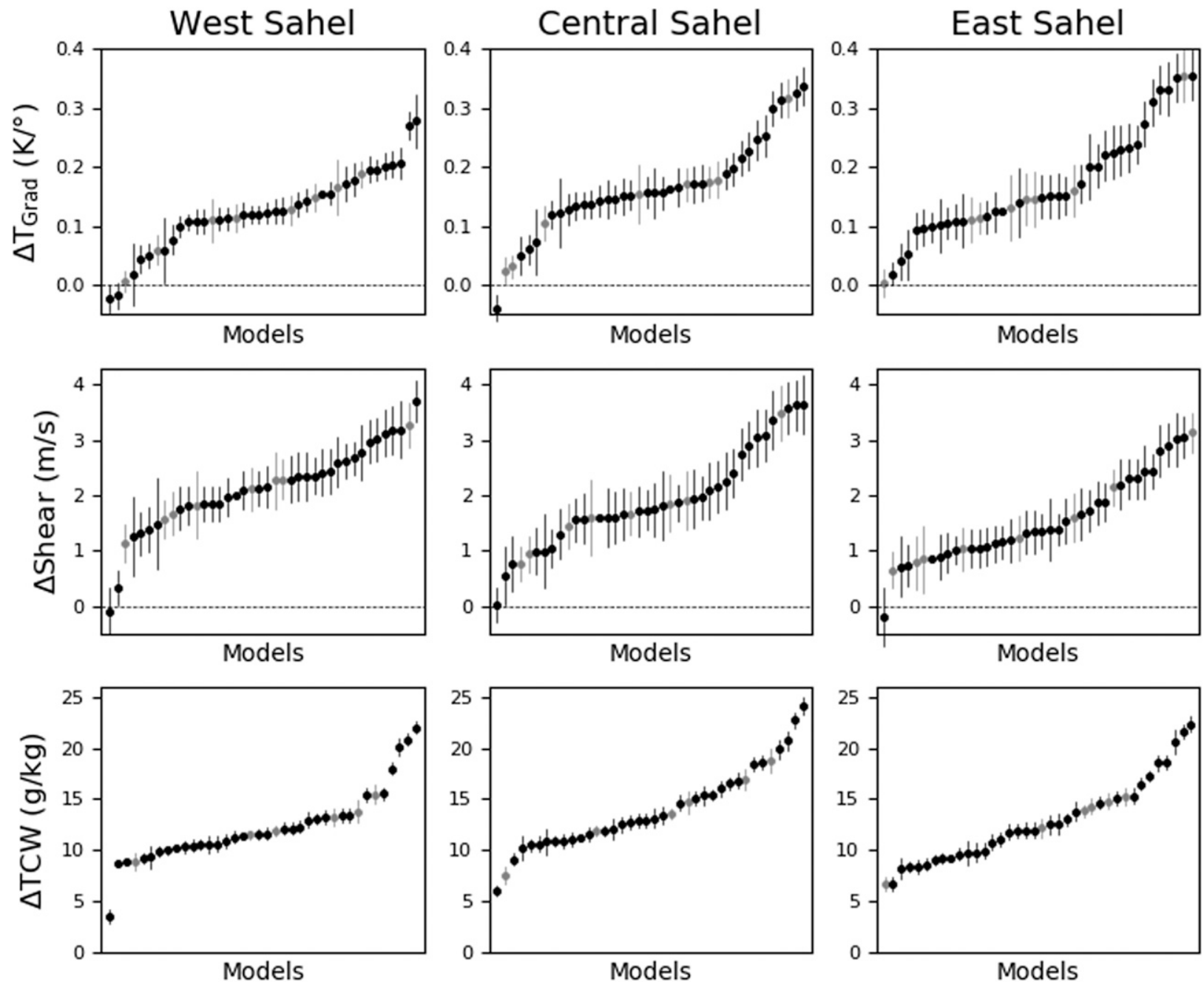

FIG. 2. Projected change in large-scale drivers of intense Sahel storms, with models (each dot) in rank order for each panel. (top) Meridional 850-hPa temperature gradient ( $T_{\mathrm{Grad}}$ ); (middle) 925-600-hPa vertical zonal wind shear (Shear); (bottom) total columnintegrated water vapor (TCW). Data are averaged over the (left) West Sahel, (center) Central Sahel, and (right) East Sahel, and over JulySeptember. Vertical lines show \pm 2 standard deviations of natural variability, except MRI-ESM1 for which piControl data are unavailable. All TCW data are missing for EC-EARTH and HadGEM2-AO. Gray dots and lines show models absent from the 32-model subset.

regional responses entirely independent of global warming, which may encompass a mix of "slow processes" (indirect anthropogenic effects, dependent on the pattern of ocean warming) and "fast processes" driven by direct responses to anthropogenic emissions.

To help decompose the remote and regional sets of drivers of uncertainty in Sahel $\Delta T_{\text {Grad }}$, each left-hand panel of Fig. 4 shows correlations across models between a sub-Sahel $\Delta T_{\text {Grad }}$ index and the projected change in near-surface air temperature computed at each location. This elucidates the role of remote drivers, with the use of near-surface data emphasizing the role of surface coupling in many of the key processes. The largest impact of remote warming is on uncertainties in the East Sahel (lower left), with notable contributions from uncertain slow global ocean warming, the tropical east Pacific, and northern continental warming. Farther west, these remote impacts diminish, mostly becoming negligible for the West Sahel. Regarding potential regional drivers, variability in $\Delta T_{\mathrm{Grad}}$ is dominated by uncertainty in processes over the southern Sahara (at both the surface and $850 \mathrm{hPa}$, left and right panels, respectively), with substantially less influence from uncertainties farther south. This is also reflected in substantially larger intermodel variance of local warming over the northern Sahel and southern Sahara (surface and $850 \mathrm{hPa}$; not shown).

The zonal asymmetry of remote influence is examined further in Fig. 5, which computes the correlation across models between projected changes in $\Delta T_{\mathrm{Grad}}$ and global mean nearsurface air temperature $\left(\Delta T_{\mathrm{Glo}}\right)$, where $\Delta T_{\mathrm{Grad}}$ is computed over a sliding $11.25^{\circ}$ longitudinal window. Like Fig. 4, this illustrates a moderate impact of global warming uncertainties on $\Delta T_{\text {Grad }}$ over the East Sahel, then diminishing toward the West Sahel. Thus Fig. 5 also supports the section 2 definitions of the West, Central, and East Sahel (marked on Fig. 5) as regions of distinct strength of relationship with $\Delta T_{\mathrm{Glo}}$. 

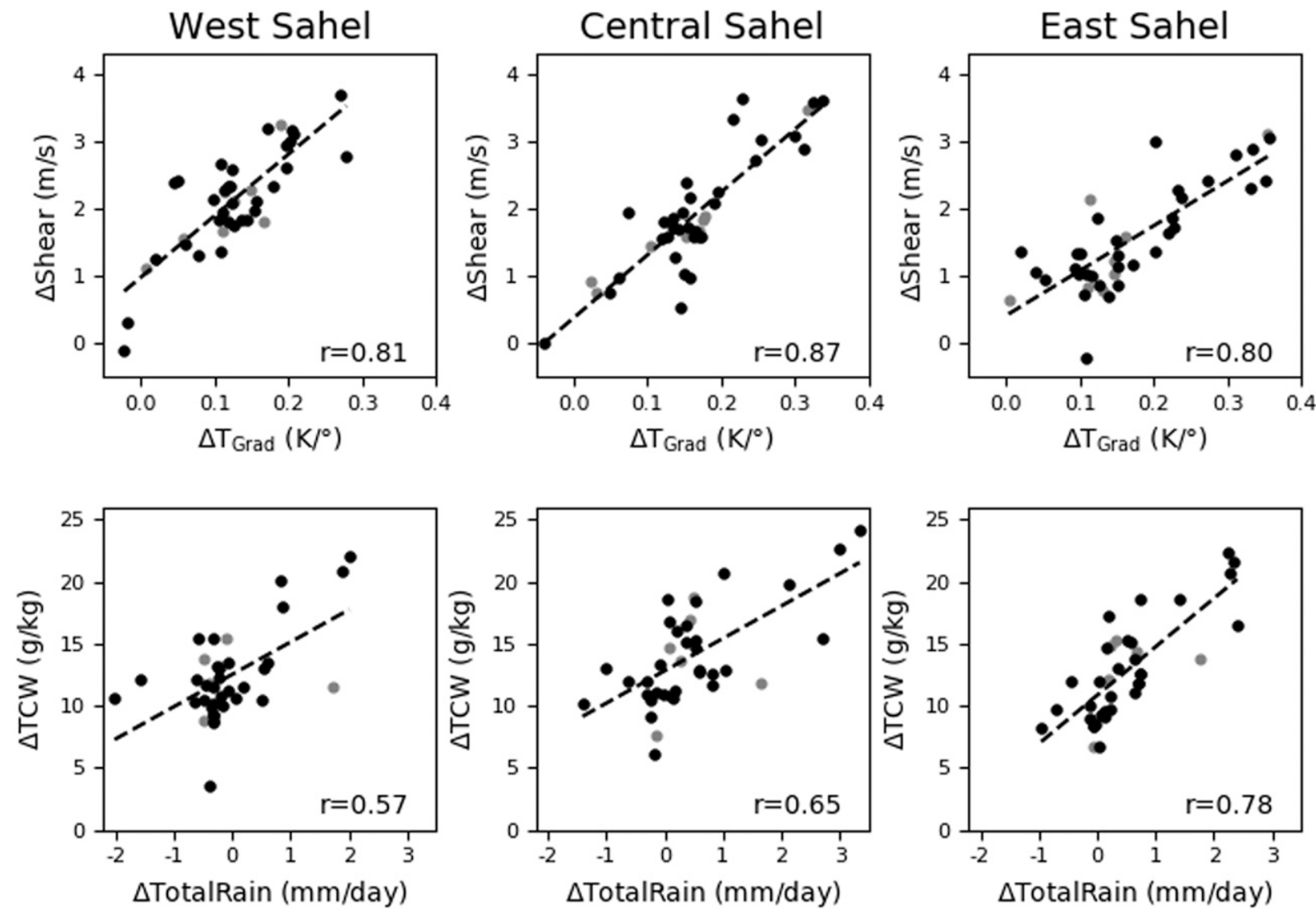

FIG. 3. Scatterplots of projected changes in (top) meridional temperature gradient vs vertical zonal wind shear and (bottom) total column-integrated water vapor vs seasonal rainfall. Data are averaged over the (left) West, (center) Central, and (right) East Sahel, and over July to September. The dashed line is the best linear fit, and printed values are intermodel correlations. Gray dots show models absent from the 32-model subset.

Further analysis of the uncertainties in regional processes and their influence on $\Delta T_{\text {Grad }}$ must now be separated from the uncertain influence of global mean warming on the Central and East Sahel. This is achieved by removing the linear intermodel regression between $\Delta T_{\mathrm{Glo}}$ and the East or Central Sahel $\Delta T_{\mathrm{Grad}}$ (but retaining the $\Delta T_{\text {Grad }}$ mean), and similarly for all other variables related to these $\Delta T_{\text {Grad }}$ indices (full field data are used for West Sahel $\Delta T_{\mathrm{Grad}}$ analysis, which is not impacted by $\Delta T_{\mathrm{Glo}}$ ) These regional components of projected anomalies are now denoted by the prefix $\Delta_{R}$. Note that if this approach is applied to a variable and location already independent of $\Delta T_{\mathrm{Glo}}$, then it has minimal impact.

The remainder of this study focuses on elucidating the causes of uncertainty in these regional drivers of $\Delta_{R} T_{\text {Grad. Prior to }}$ detailed analysis in section 4 , it is useful to examine intermodel consistency of $\Delta T_{\mathrm{Grad}}$ between the three Sahel subregions. Correlations across models between Central Sahel $\Delta_{R} T_{\mathrm{Grad}}$ and East Sahel $\Delta_{R} T_{\text {Grad }}$ or West Sahel $\Delta T_{\text {Grad }}$ are 0.86 and 0.76 , respectively. This implies that the regional drivers of intermodel variability are likely similar between subregions, and therefore subsequent sections will focus primarily on the Central Sahel, followed by brief comparisons with the East and West Sahel.

Last, we compare the strength of influence of remote and regional drivers on uncertainties in this severe storm proxy.
Intermodel correlations between $\Delta T_{\mathrm{Grad}}$ and $\Delta T_{\mathrm{Glo}}$ are 0.06 , 0.37, and 0.56 for the West, Central, and East Sahel (mirroring Fig. 5, and assuming linearity with minimal contribution of North African effects to the global mean), whereas correlations between $\Delta_{R} T_{\mathrm{Grad}}$ and local southern Saharan $\Delta_{R} T^{850}$ maximize at $0.87,0.83$, and 0.70 , respectively. This suggests that regional drivers have a larger impact on intermodel variability of $\Delta T_{\text {Grad }}$ than the remote set of drivers.

Nevertheless, regarding the secondary impact of remote uncertainties-most relevant in the East Sahel—we note that the research community has devoted, and continues to devote, significant effort to probing and constraining this driver (e.g., Armour 2017; Booth et al. 2017; Myhre et al. 2015; Stevens et al. 2016). Subsequent research should therefore integrate this understanding of global uncertainties with the outcomes of our current study.

\section{Regional drivers of uncertainty in lower tropospheric warming}

Figure 6 summarizes the processes that will be shown to determine the intermodel variability of projected changes in Central Sahelian meridional temperature gradient and the southern Saharan warming that was identified above as the 
West Sahel $\Delta \mathrm{T}_{\text {Grad }} \mathrm{v}$ Local $1.5 \mathrm{~m} \Delta \mathrm{T}$

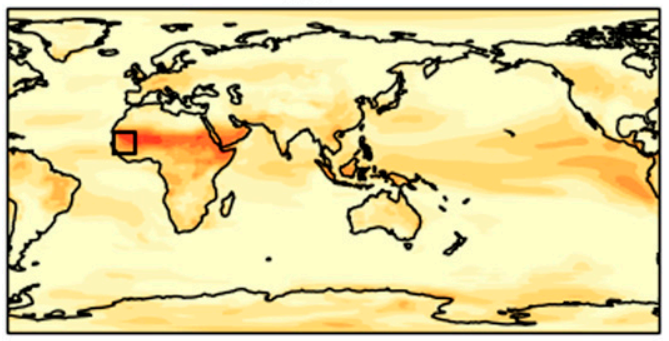

Central Sahel $\Delta \mathrm{T}_{\text {Grad }} \mathrm{v}$ Local $1.5 \mathrm{~m} \Delta \mathrm{T}$

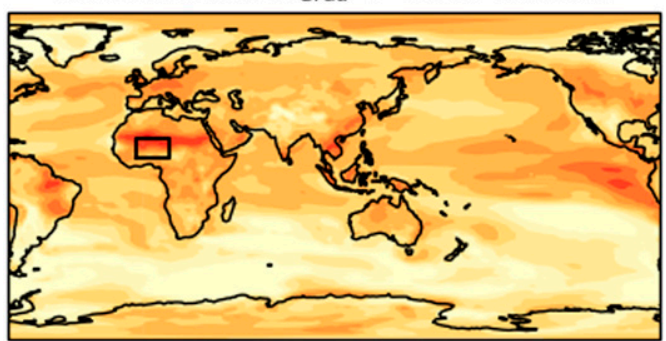

East Sahel $\Delta \mathrm{T}_{\text {Grad }} \mathrm{v}$ Local $1.5 \mathrm{~m} \Delta \mathrm{T}$

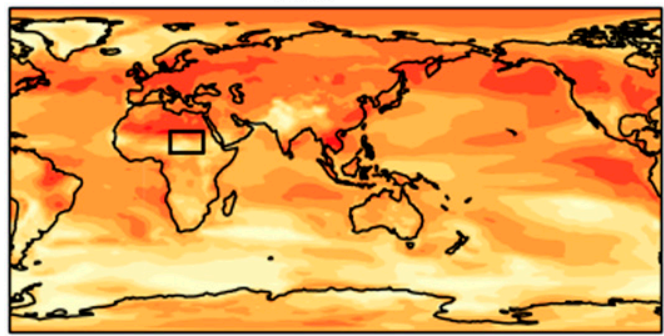

West Sahel $\Delta \mathrm{T}_{\text {Grad }} \mathrm{V}$ Local $850 \mathrm{hPa} \Delta \mathrm{T}$

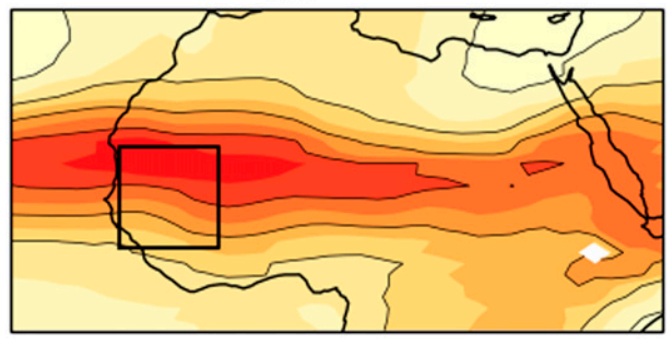

Central Sahel $\Delta \mathrm{T}_{\text {Grad }} \mathrm{v}$ Local $850 \mathrm{hPa} \Delta \mathrm{T}$

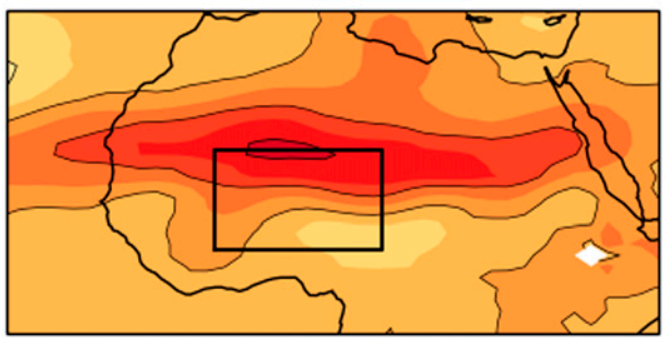

East Sahel $\Delta \mathrm{T}_{\text {Grad }} \mathrm{v}$ Local $850 \mathrm{hPa} \Delta \mathrm{T}$

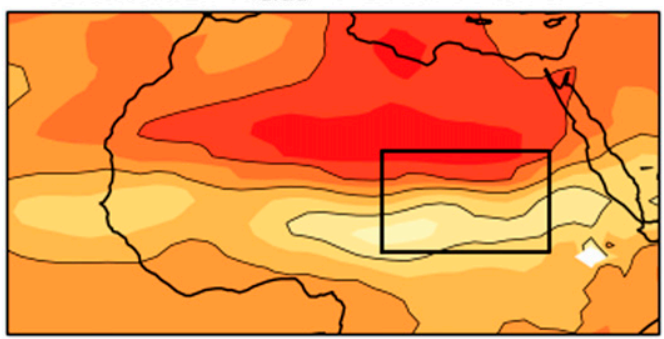

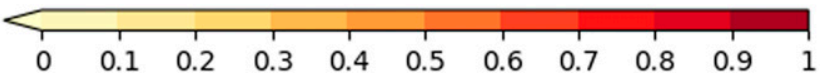

FIG. 4. Intermodel index-to-point correlations between the projected change in meridional temperature gradient for each Sahelian region (from top to bottom) and the projected change in either (left) local near-surface air temperature or (right) $850-\mathrm{hPa}$ temperature. Correlations are computed across 40 models at each grid point using near-surface or 850-hPa temperature data at that point, and all data are averaged over July-September. Boxes show the three Sahel regions, and right panels include contours at intervals of 0.2.

immediate regional source of $\Delta T_{\mathrm{Grad}}$ uncertainties. Illustrating these research outcomes upfront may provide a reference point during the following detailed description of the analysis from which it derives; we will return to this schematic in the concluding section. At the center of Fig. 6 (highlighted by blue boxes) are the twin "target indices" that we wish to understand, Sahelian $\Delta T_{\text {Grad }}$ and southern Saharan $\Delta T$. The primary driver of their uncertainties will be shown to be intermodel variations in the strength of a regional lower tropospheric warming-advection-circulation feedback (Fig. 6, top right); the underpinning analysis and more detailed interpretation is described in section 4a. Local land surface interactions will also be shown to be important, but with limited coherence across models with the exception of a weak evaporative effect (lower part of Fig. 6); further detail is presented in section $4 \mathrm{~b}$. Additionally, as already discussed in section 3, important secondary roles are played by uncertain remote, often globalscale, processes (Fig. 6, top left).
To introduce the process-based regional uncertainty analysis of this section, Fig. 7 shows intermodel correlations between Central Sahel $\Delta_{R} T_{\text {Grad }}$ and projected changes in sources of lower tropospheric heating. Over the southern Sahara-where thermal anomalies are most strongly correlated with uncertainty in warming gradients (section 3) - Fig. 7 shows the dominant drivers of this uncertain local warming to be uncertain changes in thermal advection $\left(\Delta_{R} \mathbf{V} \cdot \nabla T\right.$; examined further in section $4 \mathrm{a}$, where $\mathbf{V}$ is the horizontal wind vector) as well as uncertainties in longwave (LW) heating from the southern Saharan surface (examined further in section 4b). A parallel regression analysis (Fig. S1 in the online supplemental material) shows that the intermodel variability of thermal advection is more influential toward the surface, evidenced by larger regression slopes at $925 \mathrm{hPa}$. Vertical mixing presumably transports the $925-\mathrm{hPa}$ thermal anomalies to higher levels. Much of the ensuing analysis therefore focuses on circulation change at $925 \mathrm{hPa}$ rather than at the $850-\mathrm{hPa}$ proxy for the 


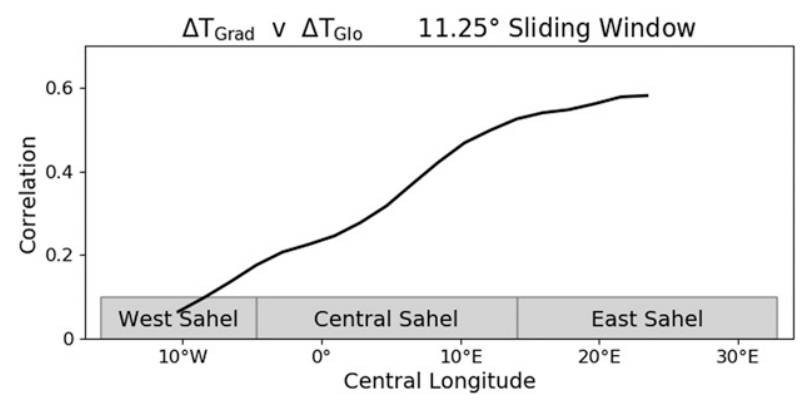

FIG. 5. Intermodel index-to-index correlations between the projected changes in meridional temperature gradient and global mean near-surface air temperature. Temperature gradients are averaged over a sliding $11.25^{\circ}$ longitudinal window, and data from the 40 models are each averaged over July-September.

surface-to-AEJ layer mean. Section 4 a does however suggest an explanation for the weaker $850-\mathrm{hPa}-\Delta_{R} T_{\mathrm{Grad}}$ relationship. Farther south, those models with larger Sahelian $\Delta_{R} T_{\text {Grad }}$ are associated with larger influx of cool moist air (primarily at 925 hPa; Fig. 7 center left), which will be shown in section 4 a to have little feedback onto $\Delta_{R} T_{\text {Grad. }}$ Last, uncertainties in anomalous surface sensible heat flux and low cloud (for which the net cloud radiative effect, NetCRE, is a proxy; Webb et al. 2006) have little coherent impact on $\Delta_{R} T_{\mathrm{Grad}}$ across models.

For the East Sahel, broadly similar conclusions are drawn (Fig. S5), although surface effects via upward LW flux are less coherent across models, and the relative impact of 850- versus 925-hPa thermal advection is closer (regression analysis not shown). For the West Sahel, uncertainties in cloud effects play an additional secondary role (Fig. S9). We have also examined the relative importance of these drivers on the vertical profile of the meridional gradient of warming uncertainties (not shown). Although broadly reflecting the above analysis of $850-\mathrm{hPa}$ warming uncertainties, total cloud cover is also important at $925 \mathrm{hPa}$ (cf. SW radiative effects on the surface to be discussed in section $4 \mathrm{~b}$ ), and uncertainty in low cloud effects (NetCRE) become more important at $700 \mathrm{hPa}$ where there is likely less impact of the vertical transport of warming from low-level thermal advection. So, although $850 \mathrm{hPa}$ is most suitable for defining a $\Delta T_{\text {Grad }}$ driver of MCS activity - as the CMIP level closest to the midpoint of the surface-to-600-hPa layer and most representative of the SAL - further examination of vertical sensitivities to its underlying drivers should be an area for further research.

\section{a. Lower-tropospheric sources of uncertainty}

Here we aim to understand the critical role of uncertainties in the projected change in low-level thermal advection revealed above. Figure 8 presents a composite analysis of low-level circulation and temperature anomalies that together determine the thermal advection anomalies. Models are classified by their projected change in Central Sahel $\Delta_{R} T_{\mathrm{Grad}}$, then averaging the 14 models $(\sim 33 \%)$ with highest $\Delta_{R} T_{\mathrm{Grad}}$ and the 14 models with lowest $\Delta_{R} T_{\text {Grad. }}$ The ensemble mean historic climatology (top left, using all 40 models) illustrates the mean position of the monsoon trough, the West African monsoon (WAM) southwesterly flow into the Sahel, and the opposing northeasterly flow from the Sahara. Climatological thermal advection (top center) is predominantly negative at $925 \mathrm{hPa}$ (offsetting strong heating from the desert surface) but is substantially weaker along the southern edge of the Sahara, or weakly positive along the western and eastern extremities of the southern Sahara. This band approximately follows the thick dashed line, which marks
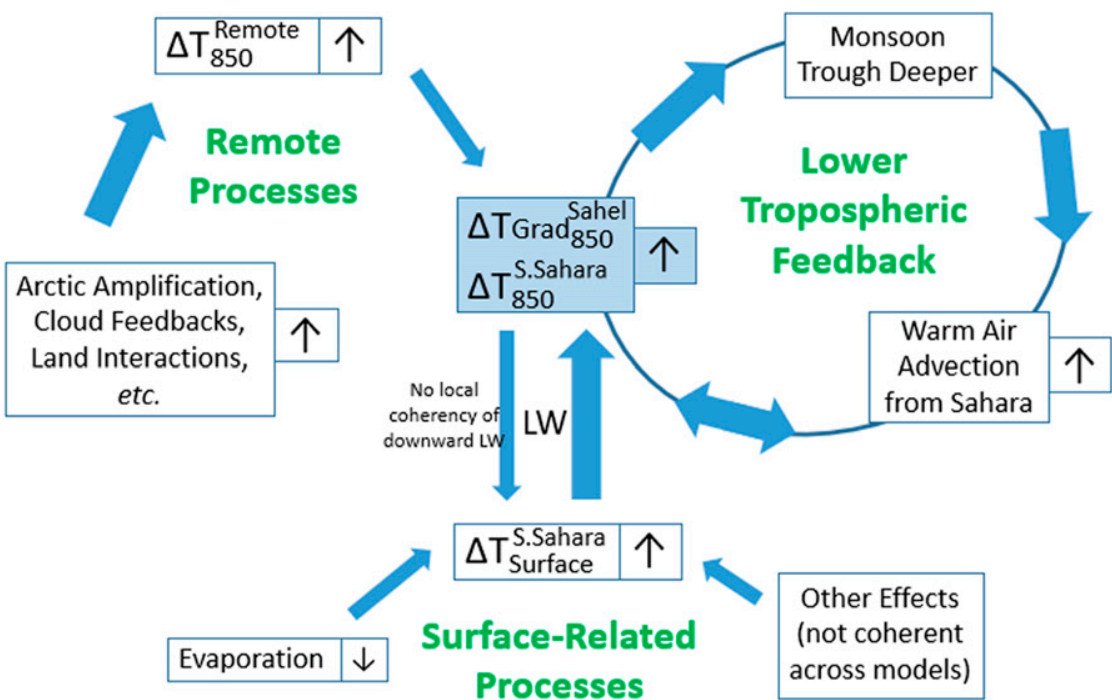

FIG. 6. Simplified schematic of the uncertain mechanisms driving intermodel variability of projected changes in Central Sahelian meridional temperature gradient $\left(\Delta T_{\mathrm{Grad}}\right)$ and southern Saharan surface temperature $(\Delta T)$. Illustrated as a comparison between models with high vs low $\Delta T_{\mathrm{Grad}}$ and $\Delta T$. Blue boxes emphasize the focus on $\Delta T_{\mathrm{Grad}}$ and $\Delta T$, blue arrows show inferred causal direction, with thickness suggesting relative importance, and black arrows in boxes show projected increases or decreases. See text for full discussion. 

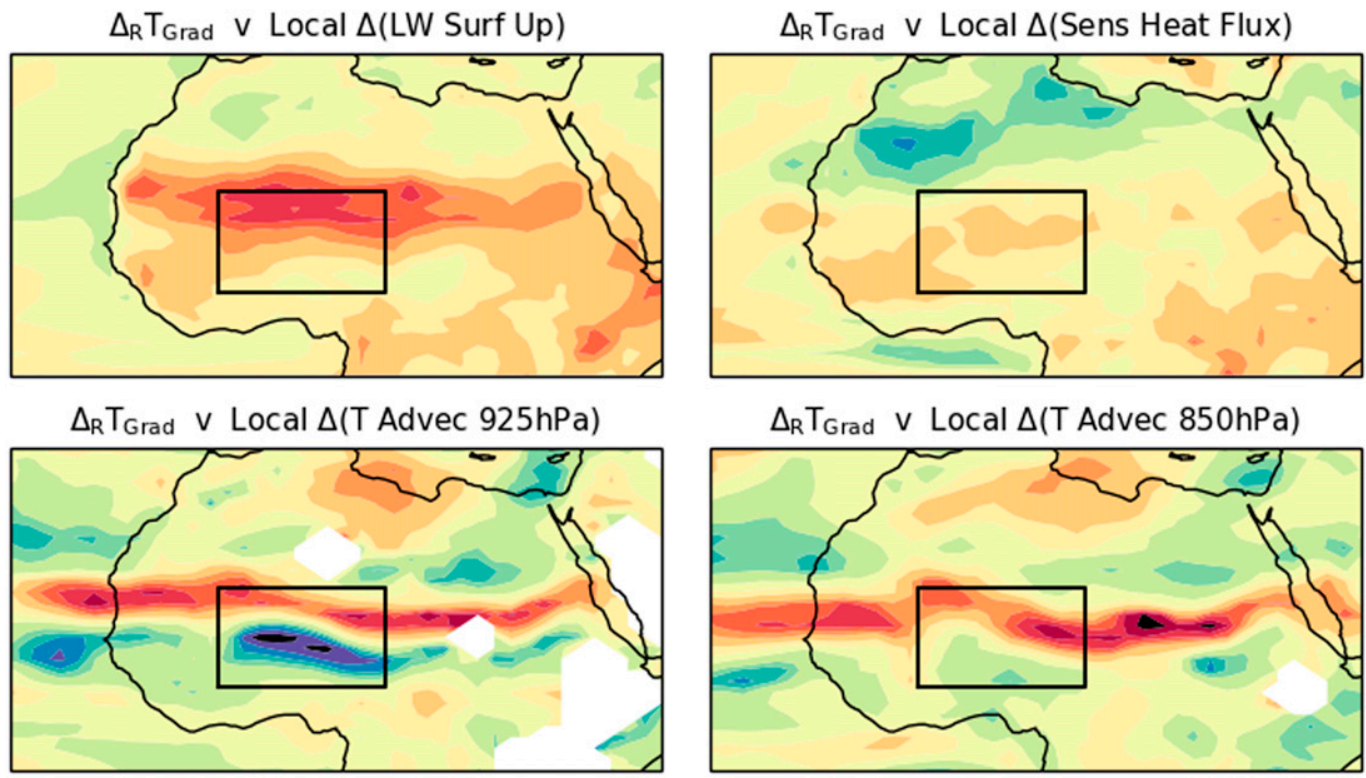

$\Delta_{R} T_{\text {Grad }} v$ Local $\Delta$ (Cloud Fraction)

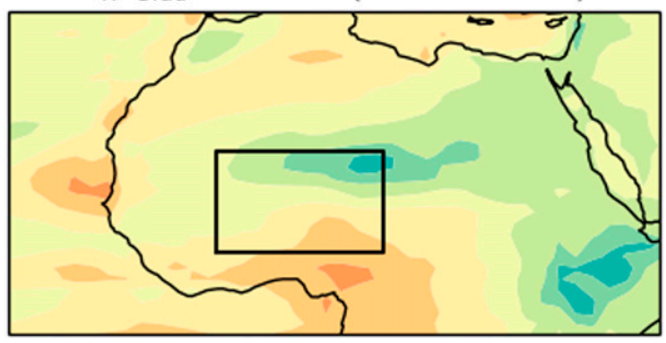

$\Delta_{R} T_{\text {Grad }} \vee$ Local $\Delta$ (NetCRE)
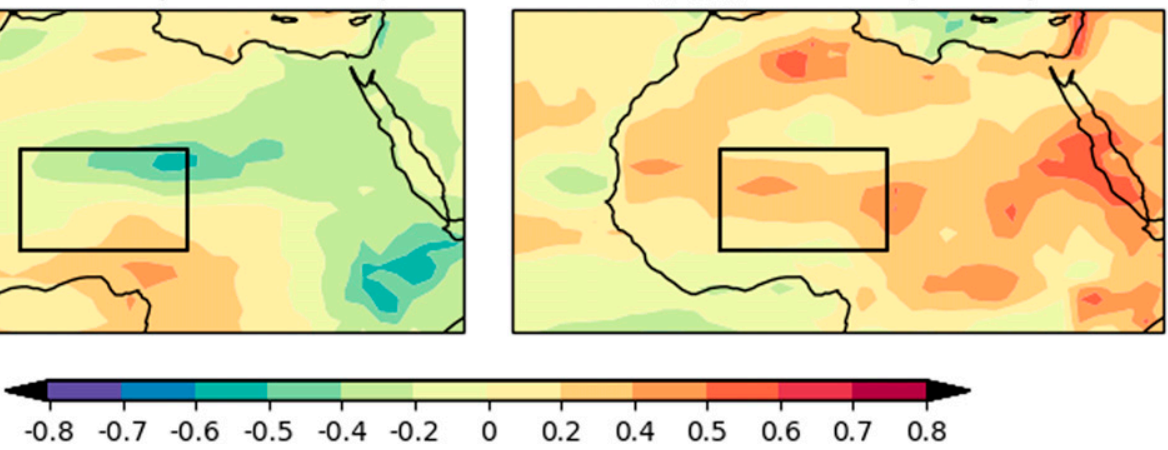

FIG. 7. Maps of index-to-point intermodel correlations between projected changes in Central Sahel meridional temperature gradient and changes in local values of potential drivers of lower-tropospheric heating; see panel titles. Correlations are computed across 32 models at each grid point, data are averaged over July-September, and the effects of global processes have been removed. Grid boxes with more than $50 \%$ of models below the topographic surface are masked. The box marks the Central Sahel.

the climatological location of the ensemble mean monsoon trough (latitudes of minimum SLP), identically placed in all panels for consistent orientation.

Future projections in both composites exhibit intense Saharan warming due to "desert amplification" (Fig. 8 right column, rows $2-5$; locally up to $6^{\circ} \mathrm{C}$ averaged over all models). Southward movement of this more strongly heated desert air, by the climatological northeasterly flow, is however impeded by the opposing monsoon flow, with the result that $\Delta_{R} T_{\text {Grad }}$ intensifies (right column, rows 4 and 5). In the southern Sahara, the combination of climatological northeasterlies and enhanced $\Delta_{R} T_{\mathrm{Grad}}$ leads to a band of further local warming by enhanced thermal advection (center column, rows 4 and 5). This warming (and the wider Saharan warming), seen in both composites, then causes a reduction in surface pressure over the desert (left column, rows 4 and 5), and hence a deepening and slight northward shift of the monsoon trough (left column, rows 2 and 3 ).
Focusing on the individual composites and their differences, the high composite models, by definition, exhibit larger $\Delta_{R} T_{\mathrm{Grad}}$ than the low composite models, with these gradient anomalies also extending farther south. Hence, the high composite models exhibit a stronger and more southward band of positive thermal advection anomalies (cf. rows 4 and 5, center column of Fig. 8, and similarly Fig. S2, which is a zoom of Fig. 8), again impeded by the opposing monsoon flow. This amplifies the southern Saharan warming in high versus low composite models (i.e., describes a stronger warmingadvection feedback; Fig. 8 and Fig. S2, lower right). This is then exacerbated by further deepening of the monsoon trough in high composite models, strengthening the flow of desert air on its northern side (Fig. S2, lower left) across the climatological temperature gradient, further enhancing the warming via thermal advection, and then in turn also causing further deepening of the monsoon trough. 

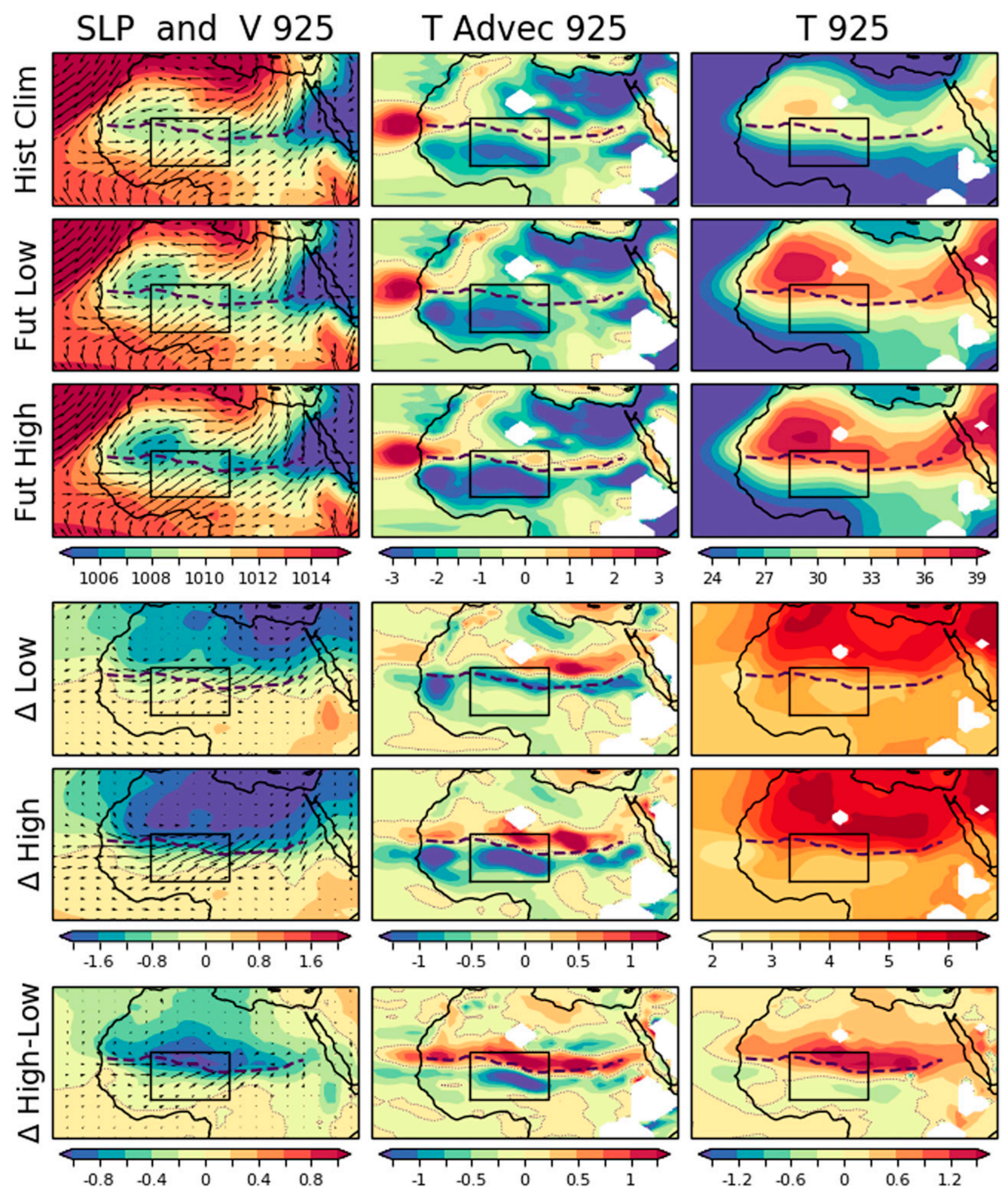

FIG. 8. Composite maps of (left) sea level pressure (SLP; hPa) and 925-hPa winds (V925), (center) 925-hPa thermal advection (TAdvec; $\mathrm{K} \mathrm{day}^{-1}$ ), and (right) 925 -hPa temperature $\left(T ;{ }^{\circ} \mathrm{C}\right.$ ). (row 1$)$ Historic climatology averaged over all 40 models; (row 2 ) future projection for low composite models; (row 3 ) future projection for high composite models; (row 4) projection anomalies (future minus historic) for low composite models; (row 5) projection anomalies for high composite models; (row 6) projection anomalies for high minus low composites. Low and high composites are computed as averages over the 14 models with lowest and highest Central Sahel anomalous (future minus historic) meridional temperature gradient. All data are averaged over July-September. The effects of global processes have been removed and to attain a consistent baseline for the projection composites (rows 2 and 3), these composites are recomputed by adding their 
Local $\Delta \mathrm{T} 925 \mathrm{hPa} v$ Local $\Delta \mathrm{q} 925 \mathrm{hPa}$

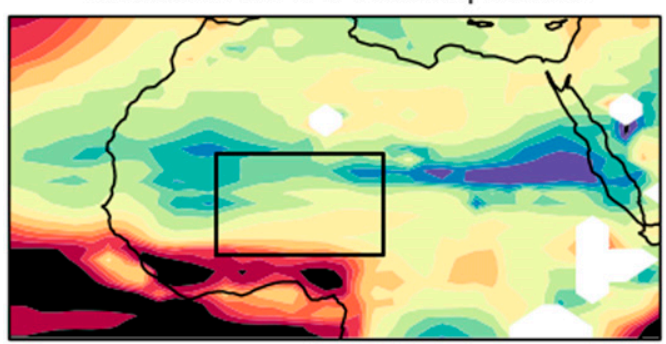

Local $\Delta$ T Advec $925 \mathrm{hPa} v$ Local $\Delta$ (LW Surf Up)

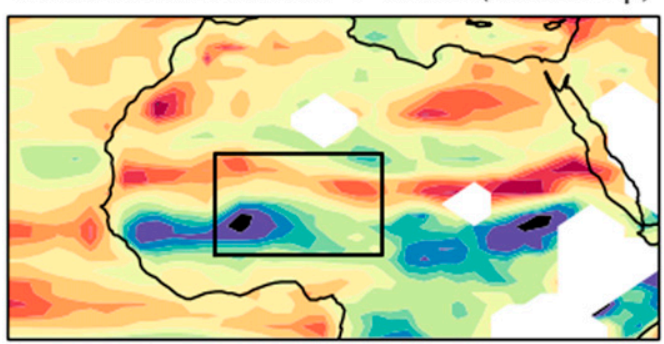

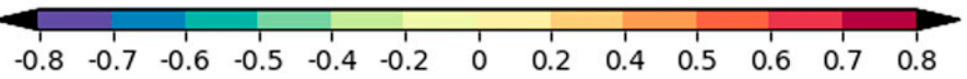

FIG. 9. Maps of point-to-point intermodel correlations (left) between projected changes in 925-hPa temperature and specific humidity and (right) between projected changes in $925-\mathrm{hPa}$ thermal advection and upward surface LW. Correlations are computed across 32 models, with both variables collocated at the same grid point. All data are averaged over July-September, the effects of global processes have been removed, and projection anomalies are computed as future-minus-historical, except that specific humidity anomalies are scaled by the historic climatology. For tropospheric data, grid boxes with more than $50 \%$ of models below the topographic surface are masked, and the box marks the Central Sahel.

In summary, this characterizes a warming-advection-circulation feedback whereby the southwestward advection of thermally amplified desert air is inhibited by the opposing WAM, forming a narrow warming-advection band, further exacerbated by a deepening monsoon trough (Fig. 6, top right). This feedback functions more strongly in some models than others, presumably partly dependent on each model's thermal dissipation processes in this region, such as mixing from the low-level cyclonic circulation (Nicholson 2013) or African easterly waves. Importantly, although this feedback is initiated by the Saharan warming, it does not represent intermodel variability in the strength or extent of the desert amplification mechanism, but rather its relative strength among models is determined more by local processes specific to the southern Sahara. This is evidenced by 1) the absence of high intermodel correlations between $\Delta T_{\text {Grad }}$ and local $\Delta T$ in the central Sahara, indicating that variations in central Saharan $\Delta T$ cannot be the main driver of $\Delta T_{\mathrm{Grad}}$, and 2) negative intermodel correlations between collocated changes in low-level temperature and humidity over the southern Sahara (Fig. 9, left), contrary to the reliance of the desert amplification mechanism on concomitant increases in temperature and humidity (Zhou 2016; Vizy and Cook 2017), with these negative correlations instead being consonant with the proposed role of advection of hot dry desert air.

For the southern Sahel, in the majority of models, the primary consequence of the deeper trough and enhanced temperature gradient is an enhanced WAM (Fig. 8, left column, rows 4 and 5). This response is amplified in high $\Delta_{R} T_{\text {Grad }}$ models, and then affects intermodel variability of local warming via two competing processes. One is that these models exhibit larger increases in lower tropospheric humidity (Fig. 10, top left), acting to enhance the downward LW flux (Fig. 10, top right) (noting that $\Delta_{R} q^{925}$ is plotted here as a percentage change; e.g., Wei et al. 2017), so contributing to surface warming, enhanced upward LW flux and potentially lower tropospheric warming. The second, offsetting, process is larger increases in cool air advection in the high $\Delta_{R} T_{\mathrm{Grad}}$ models (Fig. 8, center column, rows 4-6). Since the upward LW flux and thermal advection are anticorrelated across models (Fig. 9, right; due to the opposing moisture and thermal effects of changes in WAM strength), the net result is a tendency for cancellation between these two processes, and so little coherent net impact on the regional component of southern Sahel lower tropospheric warming (Fig. 8 lower right and Fig. 10 center left). So overall, southern Sahelian processes neither enhance nor notably reduce the impact of the southern Saharan warming-advectioncirculation feedback, and hence this southern Saharan feedback becomes the dominant regional lower-tropospheric source of uncertainty that drives intermodel variability in $\Delta_{R} T_{\text {Grad }}$ (Fig. 10, center left).

A somewhat similar view emerges from analysis of $850-\mathrm{hPa}$ thermal advection and temperature (Fig. S3), except that the thermal advection differs less between composites, concomitant with its weaker relationship with $\Delta_{R} T_{\text {Grad }}$ noted above. This may be because the circulation component of the southern Saharan feedback is absent (Fig. S3, lower left), which in turn derives from the role of the thermal low, which exhibits positive ensemble mean anomalies at $850 \mathrm{hPa}$ (i.e., subsidence; not shown) in contrast to negative height and pressure anomalies near the surface. Farther south, cool air advection is climatologically and

respective models' projection anomalies to the 40-model mean historic climatology. Wind vectors are plotted at alternate grid points, and grid points with more than $50 \%$ of models below the topographic surface are masked. The box marks the Central Sahel, dotted lines highlight zero contours, and for consistent orientation across all panels the thick dashed line marks the climatological monsoon trough. 


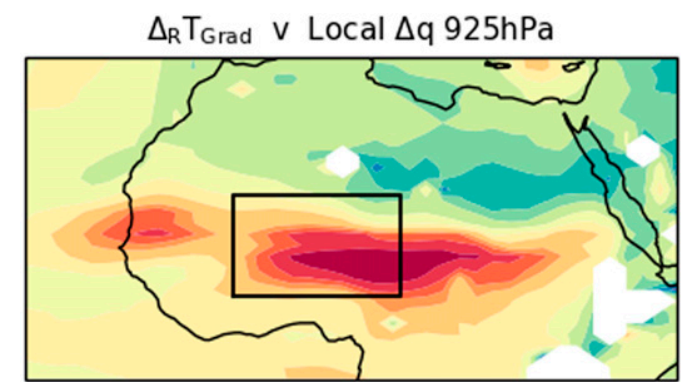

$\Delta_{R} T_{\text {Grad }} v$ Local $\Delta($ LW Surf Down Clear-Sky)
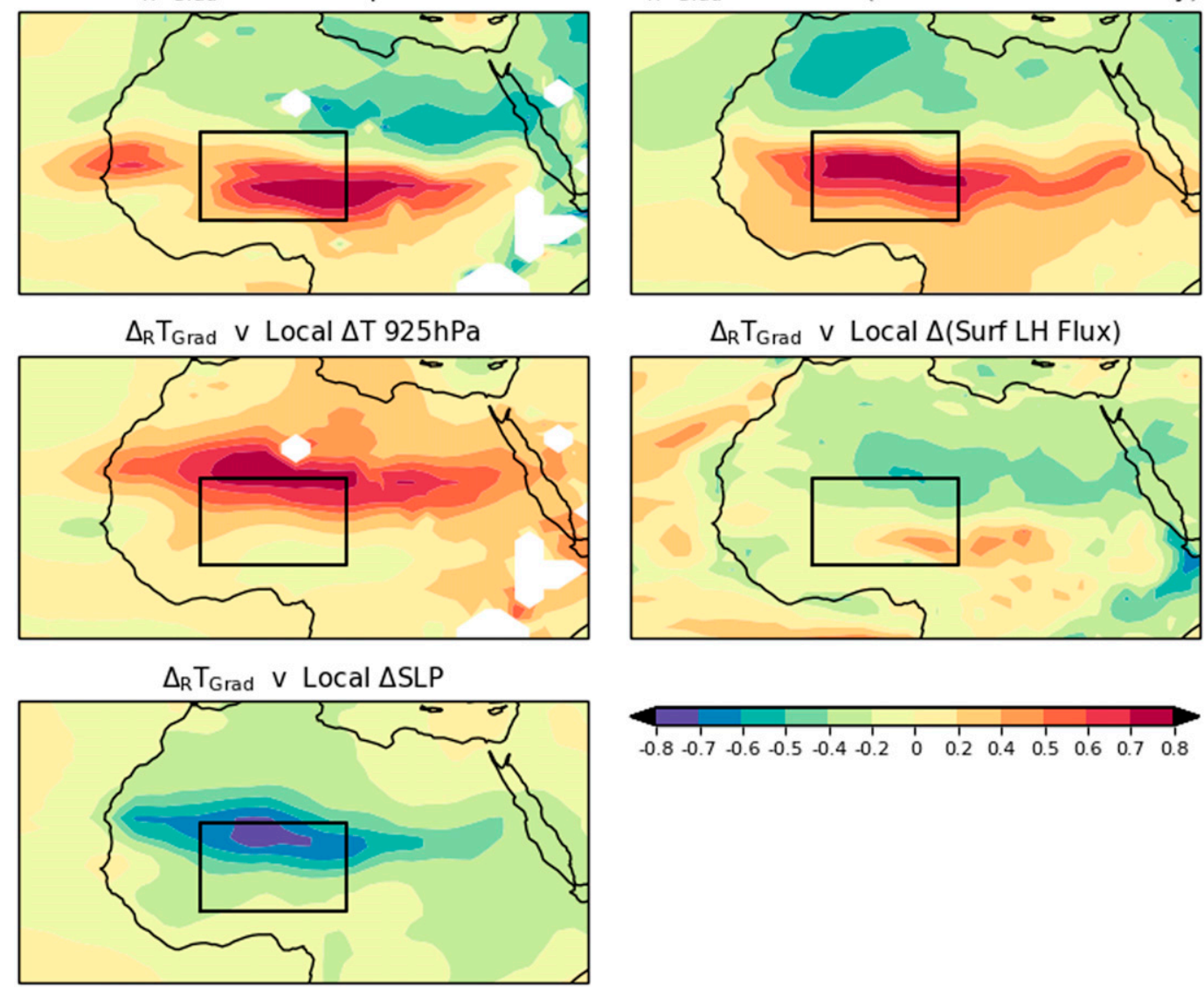

FIG. 10. Maps of index-to-point intermodel correlations between projected changes in Central Sahel meridional temperature gradient and changes in local values of other variables; see panel titles. Correlations are computed across 32 models at each grid point, data are averaged over July-September, and the effects of global processes have been removed. Projection anomalies are computed as future-minus-historical, except that specific humidity anomalies are scaled by the historic climatology. For tropospheric data, grid boxes with more than $50 \%$ of models below the topographic surface are masked. The box marks the Central Sahel.

anomalously substantially weaker than at $925 \mathrm{hPa}$, and penetrates less far north, so that 850 -hPa processes over the southern Sahel again have little impact on intermodel variability of $\Delta_{R} T_{\text {Grad}}$.

These findings are all very similar for the East and West Sahel (Figs. S6, S7, S10, S11), except that for both regions the opposing processes in the southern Sahel are both weaker than for the Central Sahel. We also note strong coastal gradients in the far west, further suggesting the dominant role of uncertain landbased, rather than marine-based, climate change mechanisms.

\section{b. Land surface interactions over the southern Sahara}

Figure 7 showed that uncertainties in Central Sahel $\Delta_{R} T_{\text {Grad }}$ are partly driven by intermodel variations in the surface warming $\left(\Delta T_{\text {Surf }}\right)$ of the southern Sahara. Hence, Fig. 11 and Fig. S4 examine the causes of this surface intermodel variability, that is, the role of latent and sensible heat fluxes, downward LW flux, net shortwave (SW) flux, and the clear-sky and cloudy components of the surface radiative fluxes. These are primarily balanced by intermodel variations in LW emissions from the land surface (Fig. 7 top left). Data are averaged over the same longitudes as the Central Sahel, but a latitude range is defined by the region of highest $\Delta T_{\mathrm{Grad}}-\Delta T_{\text {Surf }}$ correlations (Fig. 4 center left), encompassing grid box centers from $18.75^{\circ}$ to $22.5^{\circ} \mathrm{N}$ inclusive (and similarly for the western and eastern southern Sahara: $17.5^{\circ}-21.25^{\circ} \mathrm{N}$ and $18.75^{\circ}-22.5^{\circ} \mathrm{N}$, respectively).

First, from a perspective that includes global mean effects, Fig. S4 shows that the modeling uncertainty of the southern Saharan surface is dominated by uncertainties in clear-sky incoming LW radiation. Hence, intermodel variations in the amplitude of LW coupling between surface and lower troposphere are critical in this mixed picture of remote and regional drivers of uncertainty. A secondary contributor is a small opposing effect from intermodel variations in clear-sky SW surface heating, noting the smaller $x$-axis range of this Fig. S4 panel; this may be due to the effect of uncertainties in globalmean clear-sky SW absorption (DeAngelis et al. 2015). 

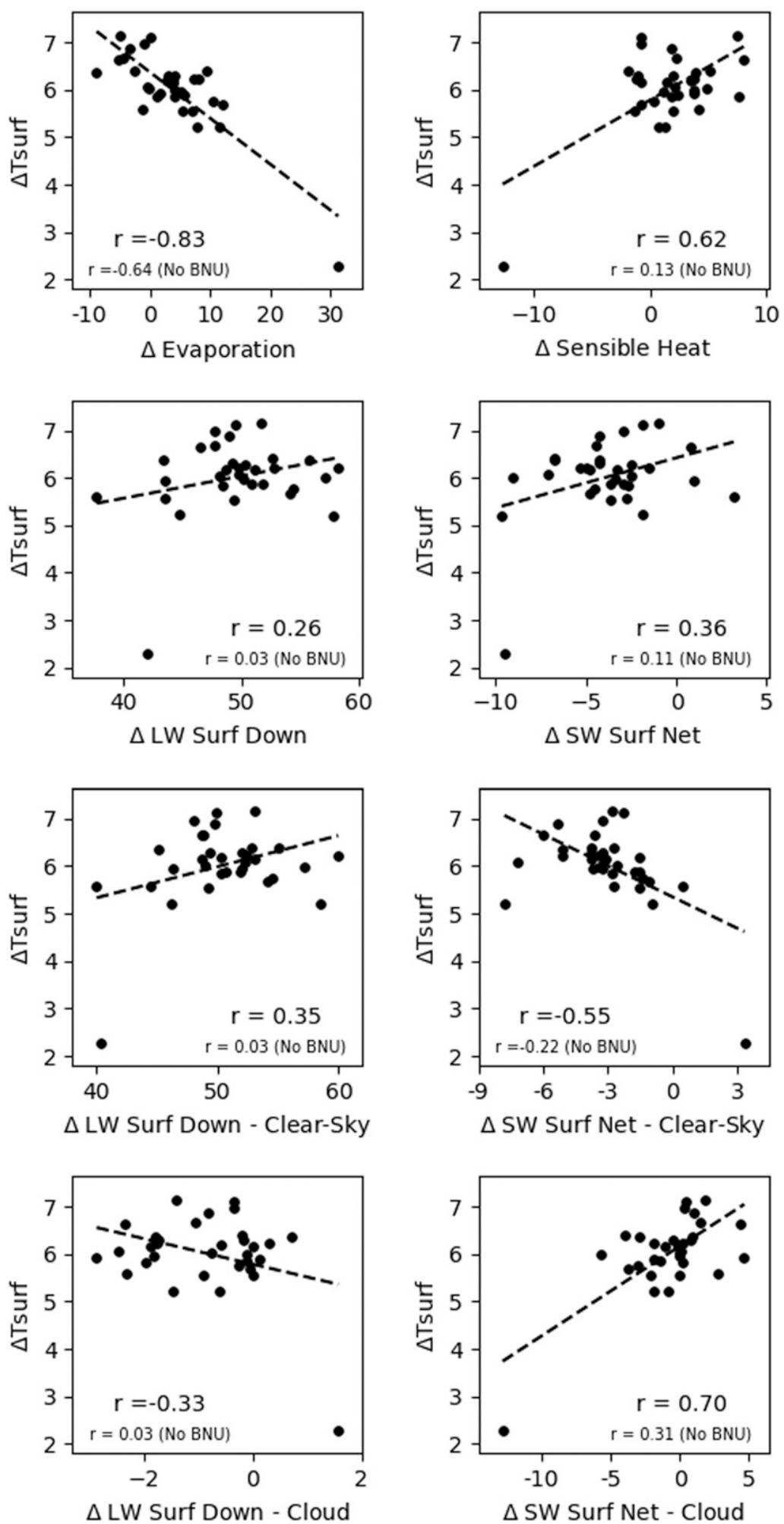

FIG. 11. Scatterplots of projected changes in surface energy budget components ( $x$ axis) vs southern Saharan surface temperature. Data are averaged over the central southern Sahara (defined in section $4 b$ ) and July-September. Correlations are computed across 32 models, and the effects of global processes have been removed. The dashed line is the best linear fit, and printed values are intermodel correlations. Net SW clear-sky-cloudy partitioning is computed by duplicating that of downward SW. 
Focusing on only the regional contributions to uncertainties in southern Saharan $\Delta T_{\text {Surf }}$, Fig. 11 paints a different picture. Intermodel variability in regional processes here are not coherently influenced by uncertainties in clear-sky incoming LW (i.e., the LW coupling effect in the southern Sahara is due only to the global mean contribution). This likely reflects the local anticorrelation between $\Delta_{R} T^{925}$ and $\Delta_{R} q^{925}$ (Fig. 9, left panel) due to intermodel variations in hot dry Saharan advection, whereby the temperature and moisture effects induce opposing changes in LW emissions. Furthermore, Fig. 11 also reveals one model to be a substantial outlier, which we suggest warrants separate discussion, followed by discussion of the remaining models.

Addressing the behavior of the outlier, BNU-ESM is seen to have an exceptionally small regional component of southern Saharan warming ( 4.5 standard deviations from the ensemble mean), and indeed is the only model with less net warming in this region than the global mean (note in Fig. 11 that $\Delta_{R} T^{\text {Surf }}$ includes the ensemble mean $\Delta T_{\text {Surf }}$, and excludes only intermodel variations of $\left.\Delta T_{\mathrm{Glo}}\right)$. This unusual outcome is due to an exceptional increase in evaporation (Fig. 11, top left) and, to a lesser extent, an unusual decrease in SW surface heating due to large increases in cloud cover (not shown, and partly offset by a large increase in net SW clear-sky heating). The budget is closed by an exceptionally small increase in upward LW (not shown) and an unusual decline in sensible heat flux. This behavior relates to a large northward shift of the North African monsoon (southern Saharan JAS rainfall anomalies reach 3.5 standard deviations from the ensemble mean), demanding further examination and understanding to develop a relevant assessment of this model's performance against observations.

Examining the remaining models, those with larger evaporative anomalies $\left(\Delta_{R} E\right)$ also tend to warm less in the southern Sahara and vice versa (Fig. 11, top left; $r=-0.64$ ), although with much smaller differential evaporative forcing and impact than the BNU model. However, when $\Delta_{R} E$ is instead correlated with 850-hPa temperature gradient changes, $\Delta_{R} T_{\text {Grad }}$, the additional influence of other effects weakens the relationship so that evaporative effects become much less influential than lowertropospheric or circulation effects (cf. Fig. 10 center right with Fig. 7 center left and Fig. 10 lower left). As noted, uncertainties in incoming LW radiation do not coherently influence $\Delta_{R} T^{\text {Surf }}$, although their intermodel range of $\sim 20 \mathrm{~W} \mathrm{~m}^{-2}$ indicates that their importance is similar to that of evaporative effects. Lesser roles-again without coherency across models-are played by sensible heat flux and SW radiative effects, both with a range of $\sim 10 \mathrm{~W} \mathrm{~m}^{-2}$ (this may include, for example, the effects of model inability to adequately represent low-level clouds over West Africa; Hannak et al. 2017).

Despite this lack of coherent behavior across models for any one variable, we emphasize that uncertainties in surface processes are nevertheless an important driver of uncertainties in this large-scale severe storm driver, demonstrated by notable intermodel correlations between surface LW emissions and $\Delta_{R} T_{\text {Grad }}$ (Fig. 7, top left). Additionally, the weak positive correlations in the northern Sahel between LW emissions and 925-hPa thermal advection suggest that intermodel variations in surface processes also contribute to intermodel variability in the strength of the warming-advection-circulation feedback.
Again, similar conclusions can be drawn for the surface interactions at the longitudes of the East and West Sahel (Figs. S8 and S12). Exceptions are that for the East Sahel, evaporative effects are less coherent ( $r=-0.44$ with the outlier removed), and that a weak but coherent SW cloud effect is found in the West Sahel across all models $\left(r=0.60\right.$, range $\sim 10 \mathrm{~W} \mathrm{~m}^{-2}$ without the outlier), both commensurate with the outcomes of the East/West Sahel equivalents of Fig. 7 noted above.

\section{Summary and discussion}

This study seeks to understand the causes of modeling uncertainties in the projected change in a large-scale atmospheric driver of severe storm activity over the North African Sahel. Lower tropospheric meridional temperature gradients impact the intensity of MCSs via zonal wind shear below the AEJ and midlevel warming and drying of the Saharan air layer. Taylor et al. (2017) have shown this to be the primary driver of the recent threefold increase in the frequency of intense MCSs over the West and Central Sahel. For the coming decades, increasing atmospheric moisture content will also be a critical large-scale driver of storm intensity (e.g., Collins et al. 2013; Fitzpatrick et al. 2020), and so a parallel study is examining uncertainties in projections of this diagnostic.

The range of projected changes in $\Delta T_{\mathrm{Grad}}$ for the late twenty-first century is found to be substantially larger than natural multidecadal variability. The same is true for midcentury projections (not shown), although to a lesser extent. Hence, understanding the causes of projection uncertainties in this large-scale driver represents an important step toward potentially reducing uncertainties in future estimates of flood risk, to help guide adaptation decisions. We have focused on the Central Sahel, $4^{\circ} \mathrm{W}-13^{\circ} \mathrm{E}$, but also shown that intermodel variations and mechanisms are broadly coherent across the whole Sahel, $16^{\circ} \mathrm{W}-35^{\circ} \mathrm{E}$.

We find three main drivers of uncertainties in $\Delta T_{\text {Grad }}$, summarized in Fig. 6. First, uncertain projections in remote atmospheric warming, which includes processes such as sea ice feedbacks, the slow ocean warming, global cloud feedbacks, and remote land surface interactions (Fig. 6, top left). These have strongest impact on the East Sahel, where $\Delta T_{\mathrm{Grad}}$ and $\Delta T_{\mathrm{Glo}}$ correlate at 0.56 , with steadily diminishing impact toward the West Sahel. Constraining uncertainties in global warming projections will therefore be helpful, and indeed is the subject of much research. On the other hand, we note that some studies are instead suggesting that the CMIP5 ensemble underestimates these uncertainties (Murphy et al. 2018; Brunner et al. 2020) due to neglect of carbon cycle uncertainties, inadequate modeling of aerosol impacts in some models, and missing complementary evidence from a broader sampling of parameter uncertainties. Drawing on such work may therefore expand rather than constrain the plausible range of this component of inferred severe storm activity.

Second, we have examined regional atmospheric drivers of the uncertainties in $\Delta T_{\text {Grad }}$ (Fig. 6, top right). These are isolated by excluding intermodel variations in $\Delta T_{\mathrm{Glo}}$ via a linear regression approach. In the southern Sahel, uncertainties in lower-tropospheric warming contribute little to $\Delta T_{\mathrm{Grad}}$ uncertainty, due to a regional negative feedback. Here models 
with larger $\Delta_{R} T_{\text {Grad }}$ induce greater strengthening of the monsoon flow, leading to larger increases in lower-tropospheric humidity and hence surface LW exchange and warming, but approximately cancelled by larger increases in cool air advection.

So, uncertain warming over the southern Sahara and northern Sahel is found to be the primary driver of the regional component of $\Delta T_{\text {Grad }}$ uncertainties. This uncertainty appears to be primarily determined by a lower tropospheric warming-advection-circulation feedback, specific to a narrow zonal band along the southern Sahara, which varies in strength between models. This does not relate to the "desert amplification" mechanism seen in the ensemble mean, but instead depends on model variations in local thermal advection and circulation change, evidenced by a lack of intermodel correlation (in fact anticorrelation) between lower tropospheric moisture and temperature changes. Further work is now needed to understand the causes of these differences in feedback strength between models, and in particular to try to find parallel intermodel variability in control simulations (e.g., in the amplitude of similar feedbacks in their interannual variability or seasonal cycle) to develop an emergent constraint for assessment against observations.

The third driver of uncertainties in $\Delta T_{\mathrm{Grad}}$ is intermodel variations acting from the southern Saharan land surface (lower part of Fig. 6). We speculate these may also partly contribute to model variability in the atmospheric feedback mechanism described above, via upward LW emissions. A clear outlier in southern Saharan surface behavior is the BNUESM model for which an exceptional increase in evaporation (and a less influential exceptional increase in cloud cover) leads to an unusually small (slightly negative) regional component of southern Saharan $\Delta T_{\text {Surf }}$. Further work is now required to understand and assess the reliability of this unusual behavior. For other models, uncertainties in projected southern Saharan surface warming are dominated by evaporative and lowertropospheric processes. For the former, there is a weak tendency for the models with largest southern Saharan evaporative anomalies to exhibit a smaller regional component of $\Delta T_{\mathrm{Grad}}$. For the lower-tropospheric processes, uncertainties in incoming LW radiation do not coherently influence southern Saharan surface warming due to confounding radiative influences from uncertainties in the hot but dry Saharan air advection. This lack of overall coherence across models of surface influences on $\Delta T_{\text {Grad }}$ will make it difficult to constrain these contributions to uncertainty; each model would need to be judged individually and an assessment made of the importance of its errors for projections relative to other models.

The new understanding presented here can now be used to develop observational constraints for some or all of the above drivers of uncertainty, and then to combine these objectively, including a constraint on the range of projected increases in atmospheric moisture content. This further research must include a full analysis of the new CMIP6 simulations, alongside a more detailed understanding of zonal and vertical variations in the drivers of West African warming uncertainties and the larger sensitivity to projected cloud cover changes in some circumstances. Assessment of convection-permitting modeling will continue to be particularly informative, in particular for better understanding the drivers of future change in MCSs (cf. Fitzpatrick et al.2020), the prospects for changes in their relative importance, and potential impacts on the spatial distribution of MCSs (L. Jackson et al., unpublished manuscript). Last, additional external drivers will also need to be considered, in particular the role of anthropogenic aerosol emissions, which may enhance near-term predictability as modeling improves (e.g., Ackerley et al. 2011; Scannell et al. 2019), and landuse changes such as urbanization. Together, we believe these approaches will build a more robust view of the future risks from severe Sahelian storm activity.

Acknowledgments. We are grateful to Doug Parker for helpful discussions that contributed to this paper. Funding was provided by the U.K. Department for International Development and Natural Environment Research Council's joint Future Climate for Africa (FCFA) programme under the AMMA-2050 project, Grants NE/M019977/1 (DPR and GR) and NE/M020126/1 (LSJ), the FCFA IMPALA project, Grant NE/MO17176/1 (LSJ), the Met Office Weather and Climate Science for Service Partnership (WCSSP) South Africa project as part of the Newton Fund (DPR), and the National Science Foundation Award 1444505 (RGJF). The modeling groups listed in section 2a are gratefully acknowledged for producing and making their simulations available from http://esgf-node.llnl.gov, as is WCRP-WGCM for taking responsibility for the CMIP5 model archive and PCMDI for archiving the model output.

\section{REFERENCES}

Ackerley, D., B. B. B. Booth, S. H. E. Knight, E. J. Highwood, D. J. Frame, M. R. Allen, and D. P. Rowell, 2011: Sensitivity of 20th century Sahel rainfall to sulfate aerosol and $\mathrm{CO}_{2}$ forcing. J. Climate, 24, 4999-5014, https://doi.org/10.1175/JCLI-D-11-00019.1.

Alfaro, D. A., 2017: Low-tropospheric shear in the structure of squall lines: Impacts on latent heating under layer-lifting ascent. J. Atmos. Sci., 74, 229-248, https://doi.org/10.1175/JASD-16-0168.1.

Armour, K. C., 2017: Energy budget constraints on climate sensitivity in light of inconstant climate feedbacks. Nat. Climate Change, 7, 331-335, https://doi.org/10.1038/nclimate3278.

Berg, P., C. Moseley, and J. O. Haerter, 2013: Strong increase in convective precipitation in response to higher temperatures. Nat. Geosci., 6, 181-185, https://doi.org/10.1038/ngeo1731.

Berthou, S., E. J. Kendon, M. Roberts, D. P. Rowell, S. Tucker, and R. Stratton, 2019: Larger future intensification of rainfall in West Africa in a convection-permitting model. Geophys. Res. Lett., 46, 13 299-13 307, https://doi.org/10.1029/2019GL083544.

Biasutti, M., 2013: Forced Sahel rainfall trends in the CMIP5 archive. J. Geophys. Res. Atmos., 118, 1613-1623, https://doi.org/ 10.1002/jgrd.50206.

Booth, B. B., G. R. Harris, J. M. Murphy, J. I. House, C. D. Jones, D. M. H. Sexton, and S. Sitch, 2017: Narrowing the range of future climate projections using historical observations of atmospheric $\mathrm{CO}_{2}$. J. Climate, 30, 3039-3053, https://doi.org/ 10.1175/JCLI-D-16-0178.1.

Browning, K. A., and F. Ludlam, 1962: Airflow in convective storms. Quart. J. Roy. Meteor. Soc., 88, 117-135, https://doi.org/10.1002/ qj.49708837602.

Brunner, L., and Coauthors, 2020: Comparing methods to constrain future European climate projections using a consistent framework. J. Climate, 33, 8671-8692, https://doi.org/10.1175/ JCLI-D-19-0953.1. 
Collins, M., and Coauthors, 2013: Long-term climate change: Projections, commitments and irreversibility. Climate Change 2013: The Physical Science Basis, T. F. Stocker et al., Eds., Cambridge University Press, 1029-1136.

Cook, K. H., 1999: Generation of the African easterly jet and its role in determining West African precipitation. J. Climate, 12, 1165-1184, https://doi.org/10.1175/1520-0442(1999)012<1165: GOTAEJ $>2.0 . \mathrm{CO} ; 2$.

— , and E. K. Vizy, 2015: Detection and analysis of an amplified warming of the Sahara Desert. J. Climate, 28, 6560-6580, https://doi.org/10.1175/JCLI-D-14-00230.1.

Crook, J., C. Klein, S. Folwell, C. M. Taylor, D. J. Parker, and T. Stein, 2019: Assessment of the representation of West African storm lifecycles in convection-permitting simulations. Earth Space Sci., 6, 818-835, https://doi.org/10.1029/2018EA000491.

DeAngelis, A., X. Qu, M. D. Zelinka, and A. Hall, 2015: An observational radiative constraint on hydrologic cycle intensification. Nature, 528, 249-253, https://doi.org/10.1038/nature15770.

Engel, T., A. H. Fink, P. Knippertz, G. Pante, and J. Bliefernicht, 2017: Extreme precipitation in the West African cities of Dakar and Ouagadougou: Atmospheric dynamics and implications for flood risk assessments. J. Hydrometeor., 18, 29372957, https://doi.org/10.1175/JHM-D-16-0218.1.

Fitzpatrick, R. G. J., and Coauthors, 2020: What drives the intensification of mesoscale convective systems over the West African Sahel under climate change? J. Climate, 33, 31513172, https://doi.org/10.1175/JCLI-D-19-0380.1.

Hannak, L., P. Knippertz, A. H. Fink, A. Kniffka, and G. Pante, 2017: Why do global climate models struggle to represent lowlevel clouds in the West African summer monsoon? J. Climate, 30, 1665-1687, https://doi.org/10.1175/JCLI-D-16-0451.1.

James, R., R. Washington, and D. P. Rowell, 2014: African climate change uncertainty in perturbed physics ensembles: Implications of warming to $4^{\circ} \mathrm{C}$ and beyond. J. Climate, 27, 4677-4692, https:// doi.org/10.1175/JCLI-D-13-00612.1.

Kendon, E. J., R. A. Stratton, S. Tucker, J. H. Marsham, S. Berthou, D. P. Rowell, and C. A. Senior, 2019: Enhanced future changes in wet and dry extremes over Africa at convection-permitting scale. Nat. Commun., 10, 1794, https://doi.org/10.1038/s41467-019-09776-9.

Kharin, V. V., F. W. Zwiers, X. Zhang, and M. Wehner, 2013: Changes in temperature and precipitation extremes in the CMIP5 ensemble. Climatic Change, 119, 345-357, https:// doi.org/10.1007/s10584-013-0705-8.

Kniveton, D., E. Visman, A. Tall, M. Diop, R. Ewbank, E. Njoroge, and L. Pearson, 2015: Dealing with uncertainty: Integrating local and scientific knowledge of the climate and weather. Disasters, 39, s35-s53, https://doi.org/10.1111/disa.12108.

Knutti, R., D. Masson, and A. Gettelman, 2013: Climate model genealogy: Generation CMIP5 and how we got there. Geophys. Res. Lett., 40, 1194-1199, https://doi.org/10.1002/grl.50256.

Lafore, J.-P., and Coauthors, 2011: Progress in understanding of weather systems in West Africa. Atmos. Sci. Lett., 12, 7-12, https://doi.org/10.1002/asl.335.

— , and Coauthors, 2017: A multi-scale analysis of the extreme rain event of Ouagadougou in 2009. Quart. J. Roy. Meteor. Soc., 143, 3094-3109, https://doi.org/10.1002/qj.3165.

Laing, A. G., J. M. Fritsch, and A. J. Negri, 1999: Contribution of mesoscale convective complexes to rainfall in Sahelian Africa: Estimates from geostationary infrared and passive microwave data. J. Appl. Meteor., 38, 957-964, https://doi.org/10.1175/ 1520-0450(1999)038<0957:COMCCT>2.0.CO;2.

Laurent, H., N. D'Amato, and T. Lebel, 1998: How important is the contribution of the mesoscale convective complexes to the
Sahelian rainfall? Phys. Chem. Earth, 23, 629-633, https:// doi.org/10.1016/S0079-1946(98)00099-8.

Lobell, D. B., and S. M. Gourdji, 2012: The influence of climate change on global crop productivity. Plant Physiol., 160, 16861697, https://doi.org/10.1104/pp.112.208298.

Macadam, I., D. P. Rowell, and H. Steptoe, 2020: Refining projections of future temperature change in West Africa. Climate Res., 82, 1-14, https://doi.org/10.3354/cr01618.

Marsham, J. H., N. S. Dixon, L. Garcia-Carreras, G. M. S. Lister, D. J. Parker, P. Knippertz, and C. E. Birch, 2013: The role of moist convection in the West African monsoon system: Insights from continental-scale convection-permitting simulations. Geophys. Res. Lett., 40, 1843-1849, https://doi.org/ 10.1002/grl.50347.

Mitchell, T. D., 2003: Pattern scaling: An examination of the accuracy of the technique for describing future climates. Climatic Change, 60, 217-242, https://doi.org/10.1023/A:1026035305597.

Mohr, K. I., and C. D. Thorncroft, 2006: Intense convective systems in West Africa and their relationship to the African easterly jet. Quart. J. Roy. Meteor. Soc., 132, 163-176, https://doi.org/ 10.1256/qj.05.55.

Murphy, J. M., and Coauthors, 2018: UKCP18 land projections: Science report. Met Office, 191 pp., https://www.metoffice.gov.uk/pub/data/ weather/uk/ukcp18/science-reports/UKCP18-Land-report.pdf.

Myhre, G., O. Boucher, F.-M. Bréon, P. Forster, and D. Shindell, 2015: Declining uncertainty in transient climate response as $\mathrm{CO}_{2}$ forcing dominates future climate change. Nat. Geosci., 8 , 181-185, https://doi.org/10.1038/ngeo2371.

Nicholson, S. E., 2013: The West African Sahel: A review of recent studies on the rainfall regime and its interannual variability. Int. Scholarly Res. Not., 2013, 453521, http://doi.org/10.1155/ 2013/453521.

—, A. H. Fink, and C. Funk, 2018: Assessing recovery and change in West Africa's rainfall regime from a 161-year record. Int. J. Climatol., 38, 3770-3786, https://doi.org/10.1002/ joc.5530.

Nka, B. N., L. Oudin, H. Karambiri, J. E. Paturel, and P. Ribstein, 2015: Trends in floods in West Africa: Analysis based on 11 catchments in the region. Hydrol. Earth Syst. Sci., 19, 47074719, https://doi.org/10.5194/hess-19-4707-2015.

Panagos, P., and Coauthors, 2017: Global rainfall erosivity assessment based on high-temporal resolution rainfall records. Nat. Sci. Rep., 7, 4175, https://doi.org/10.1038/s41598-017-04282-8.

Panthou, G., T. Vischel, and T. Lebel, 2014: Recent trends in the regime of extreme rainfall in the central Sahel. Int. J. Climatol., 34, 3998-4006, https://doi.org/10.1002/joc.3984.

Parker, D. J., C. D. Thorncroft, R. R. Burton, and A. DiongueNiang, 2005: Analysis of the African easterly jet, using aircraft observations from the JET2000 experiment. Quart. J. Roy. Meteor. Soc., 131, 1461-1482, https://doi.org/10.1256/qj.03.189.

Provod, M., J. Marsham, D. Parker, and C. Birch, 2016: A characterization of cold pools in the West African Sahel. Mon. Wea. Rev., 144, 1923-1934, https://doi.org/10.1175/MWR-D15-0023.1.

Pu, B., and K. H. Cook, 2010: Dynamics of the West African westerly jet. J. Climate, 23, 6263-6276, https://doi.org/10.1175/ 2010JCLI3648.1.

Rowell, D. P., 2019: An observational constraint on CMIP5 projections of the East African long rains and southern Indian Ocean warming. Geophys. Res. Lett., 46, 6050-6058, https:// doi.org/10.1029/2019GL082847.

_ C. A. Senior, M. Vellinga, and R. J. Graham, 2016: Can climate projection uncertainty be constrained over Africa using 
metrics of contemporary performance? Climatic Change, 134, 621-633, https://doi.org/10.1007/s10584-015-1554-4.

Sanderson, B. M., R. Knutti, and P. Caldwell, 2015: A representative democracy to reduce interdependency in a multimodel ensemble. J. Climate, 28, 5171-5194, https://doi.org/10.1175/ JCLI-D-14-00362.1.

Scannell, C., and Coauthors, 2019: The influence of remote aerosol forcing from industrialized economies on the future evolution of East and West African rainfall. J. Climate, 32, 8335-8354, https://doi.org/10.1175/JCLI-D-18-0716.1.

Singleton, A., and R. Toumi, 2013: Super-Clausius-Clapeyron scaling of rainfall in a model squall line. Quart. J. Roy. Meteor. Soc., 139, 334-339, https://doi.org/10.1002/qj.1919.

Stevens, B., S. C. Sherwood, S. Bony, and M. J. Webb, 2016: Prospects for narrowing bounds on Earth's equilibrium climate sensitivity. Earth's Future, 4, 512-522, https://doi.org/ 10.1002/2016EF000376.

Szeto, K. K., and H.-R. Cho, 1994: A numerical investigation of squall lines. Part II: Mechanics of evolution. J. Atmos. Sci., 51, 425-433, https://doi.org/10.1175/1520-0469(1994)051<0425: ANIOSL $>2.0 . \mathrm{CO} ; 2$.

Takemi, T., 2007: A sensitivity of squall line intensity to environmental static stability under various shear and moisture conditions. Atmos. Res., 84, 374-389, https://doi.org/10.1016/ j.atmosres.2006.10.001.

- 2010: Dependence of the precipitation intensity in mesoscale convective systems to temperature lapse rate. Atmos. Res., 96, 273-285, https://doi.org/10.1016/j.atmosres.2009.09.002.

Taylor, C. M., and Coauthors, 2017: Frequency of extreme Sahelian storms tripled since 1982 in satellite observations. Nature, $\mathbf{5 4 4}$, 475-478, https://doi.org/10.1038/nature22069.

Taylor, K. E., R. J. Stouffer, and G. A. Meehl, 2012: An overview of CMIP5 and the experiment design. Bull. Amer. Meteor. Soc., 93, 485-498, https://doi.org/10.1175/BAMS-D-11-00094.1.
Tazan, F., A. Diarra, R. F. W. Kabore, B. Ibrahim, M. Bologo Traore, K. Traore, and H. Karambiri, 2019: Trends in flood events and their relationship to extreme rainfall in an urban area of Sahelian West Africa: The case study of Ouagadougou, Burkina Faso. J. Flood Risk Manage, 12, e12507, https:// doi.org/10.1111/jfr3.12507.

van Aalst, M., T. Cannon, and I. Burton, 2008: Community level adaptation to climate change: The potential role of participatory community risk assessment. Global Environ. Change, 18, 165-179, https://doi.org/10.1016/j.gloenvcha.2007.06.002.

Vizy, E. K., and K. H. Cook, 2017: Seasonality of the observed amplified Sahara warming trend and implications for Sahel rainfall. J. Climate, 30, 3073-3094, https://doi.org/10.1175/ JCLI-D-16-0687.1.

Webb, M. J., and Coauthors, 2006: On the contribution of local feedback mechanisms to the range of climate sensitivity in two GCM ensembles. Climate Dyn., 27, 17-38, https://doi.org/ 10.1007/s00382-006-0111-2.

Wei, N., L. Zhou, Y. Dai, G. Xia, and W. Hua, 2017: Observational evidence for desert amplification using multiple satellite datasets. Sci. Rep., 7, 2043, https://doi.org/10.1038/s41598-01702064-w.

Weisman, M. L., and R. Rotunno, 2004: "A theory for strong long-lived squall lines" revisited. J. Atmos. Sci., 61, 361382, https://doi.org/10.1175/1520-0469(2004)061<0361: ATFSLS $>2.0 . \mathrm{CO} ; 2$.

Wilcox, C., and Coauthors, 2018: Trends in hydrological extremes in the Senegal and Niger Rivers. J. Hydrol., 566, 531-545, https://doi.org/10.1016/j.jhydrol.2018.07.063.

Yang, G. Y., and J. Slingo, 2005: The diurnal cycle in the tropics. Mon. Wea. Rev., 129, 784-801, https://doi.org/10.1175/15200493(2001)129<0784:TDCITT > 2.0.CO;2.

Zhou, L., 2016: Desert amplification in a warming climate. Sci. Rep., 6, 31065, https://doi.org/10.1038/srep31065. 